\title{
Investigation of the Effects of Bandwidth and Time Delay on Helicopter Roll-Axis Handling Qualities
}

\author{
Heinz-Jürgen Pausder \\ Deutsche Forschungsanstalt für \\ Luft- und Raumfahrt e.V. (DLR) \\ Institut für Flugmechanik \\ D-3300 Braunschweig, FRG \\ and \\ Chris L. Blanken \\ Aeroflightdynamics Directorate \\ US Army Aviation and Troop Command \\ Ames Research Center \\ Moffett Field, California, USA
}

\section{ABSTRACT}

Several years of cooperative research conducted under the U.S./German Memorandum of Understanding (MOU) in helicopter flight control has recently resulted in a successful handling qualities study. The focus of this cooperative research has been the effects on handling qualities due to time delays in combination with a high bandwidth vehicle. The jointly performed study included the use of U.S. ground-based simulation and German in-flight simulation facilities. The NASA-Ames Vertical Motion Simulator (VMS) was used to develop a high bandwidth slalom tracking task which took into consideration the constraints of the facilities. The VMS was also used to define a range of the test parameters and to perform initial handling qualities evaluations. The flight tests were conducted using DLR's variable-stability BO 105 S3 Advanced Technology Testing Helicopter System (ATTHeS). Configurations included a rate command and an attitude command response system with added time delays up to 160 milliseconds over the baseline and bandwidth values between 1.5 and $4.5 \mathrm{rad} / \mathrm{sec}$. Sixty-six evaluations were performed in about 25 hours of flight time during ten days of testing. The results indicate a need to more tightly constrain the allowable roll axis phase delay for the Level 1 and Level 2 requirements in the U.S. Army's specification for helicopter handling qualities, ADS-33C.

Presented at the 18th European Rotorcraft Forum, Avignon, France, September 1992, and at Piloting Vertical Flight Aircraft: A Conference on Flying Qualities and Human Faciors, San Francisco, California, January 1993.

\section{INTRODUCTION}

An updated military rotorcraft handling qualities specification has been published and adopted by the U.S. Army Aviation and Troop Command as Aeronautical Design Standard (ADS-33) (Ref. 1). Although the ADS33 is a U.S. specification at present, the ADS-33 is of international interest and some international studies have contributed to the data bases for the definition of the requirements. The overall philosophy follows that of the fixed-wing aircraft specification, MIL-F-8785C, although specific requirements have been generated to cover helicopter characteristics and modem military helicopter missions. The ADS-33 is a mission-oriented specification, based upon the mission task elements and the cueing available to the pilot. Minimum requirements are established for control response types and their characteristics. These requirements are categorized into terms of small, moderate, and large amplitude attitude changes and are defined for comparison with the rotorcraft characteristics. This provides a quantitative assessment of the Level of rotorcraft handling qualities. These Levels are related to the Cooper-Harper handling qualities rating scale (Ref. 2), Figure 1. The small amplitude response requirements include both short-term and mid-term responses where the short-term response refers to the rotorcraft characteristics in pilot tasks such as closed-loop, compensatory tracking and the mid-term response criteria are intended to ensure good flying qualities when less precise maneuvering is required.

The requirements for the short-term response are specified in terms of a frequency based criterion called bandwidth. The frequency response data required to mea- 
sure the bandwidth parameters are defined in Figure 2. The bandwidth, $\omega_{\mathrm{BW}}$, is measured from a frequency response (Bode) plot of the rotorcraft angular attitude response to the cockpit controller input and must include all the elements in the flight control system. Generally, a good system will have a high bandwidth and a poor system will have a low bandwidth. The bandwidth criterion is an application of the crossover model concept (Ref. 3). It is based on the premise that the maximum crossover frequency that a pure gain pilot can achieve, without threatening the stability, is a valid figure-of-merit of the controlled element. Physically, low values of bandwidth indicate a need for pilot lead equalization to achieve the required mission performance. Excessive demands for pilot lead equalization have been shown to result in degraded handling qualities ratings. The efforts to develop bandwidth as a generalized criterion for highly augmented aircraft have shown that the pilots were also sensitive to the shape of the phase curve at frequencies beyond the neutral stability frequency, $\omega_{180}$. This is addressed by the phase delay parameter, $\tau_{p}$, as defined in Figure 2. Large values of phase delay can arise from many sources, among which are the high order rotor response, control actuator dynamics, filters, and computational time delays. An aircraft with a large phase delay may be prone to pilot induced oscillations (PIO).

As previously stated, ADS-33 is a mission-oriented handling qualities specification and hence, the control response requirements are a function of the degree of divided attention, the visual environment, and the agressiveness demanded in the mission task element (MTE). The forward flight (> 45 knots) bandwidth criteria for the roll axis are shown in the Figure 3. Three sets of limits are specified: the more stingent limits apply to the air combat MTEs and the more relaxed boundaries cover all other MTEs. For divided attention operations (specifically IMC flight), the more relaxed bandwidth values are combined with the more stringent phase delay requirements.

The air combat boundaries are mainly based on a ground-based simulation study. The boundaries for all other MTEs were primarily established from flight tests with helicopters having relatively low inherent roll and pitch damping which result in low bandwidth. Also, the evaluation tasks appear to have been low-precision and moderate or large amplitude tasks. Some recent, but limited data, has indicated that some refinement in these boundaries may be necessary in the region of high bandwidth and high phase delay. Helicopters having a large flapping hinge offset and full authority digital control systems have this potential.

Under the U.S./German Memorandum of Understanding (MOU) for cooperative research in helicopter flight control, the U.S. Army Aviation and Troop Command's Aeroflightdynamics Directorate and the German's DLR Institute for Flight Mechanics have been performing research in handling qualities. The most recent task has been to study the effects on handling qualities due to time delays in combination with a high bandwidth response vehicle. Specifically, the effect of time delay in roll axis tasks in forward flight (around 60 knots) has been investigated. The technical approach has been to use the U.S. ground-based simulator to define the piloting task and to explore the scope of the variation of system configurations and then use the German helicopter inflight simulator ATTHeS for the evaluation flight tests while covering a more finely meshed set of configurations.

This paper will discuss the existing data base, the approach used to develop a task specifically adapted for the in-flight simulation, the complementary use of the NASA-Ames ground-based Vertical Motion Simulator (VMS) and the DLR Advanced Technology Testing Helicopter System (ATTHeS) in-flight simulator, and the handling qualities results.

\section{DISCUSSION OF EXISTING DATA}

The ADS-33 forward flight roll axis bandwidth criteria in Figure 3 are divided into three sets of limits covering the effects of task bandwidth and pilot attention. The requirements are applied for rate command and attitude command response types. Figure 4 illustrates the influences of response parameters. For a first order rate command and a second order attitude command response type, the bandwidth and phase delay values are mapped by varying the damping or frequency and time delay parameters. The discussion of the existing data will focus on the air combat limits, the limits for all other MTE's - VMC and fully attended operations, some miscellaneous helicopter data, and related fixed wing requirements.

\section{Air Combat Requirements}

As previously stated, the roll-axis air combat bandwidth limits were established from a ground-based simulation study of yaw axis requirements for air combat (Ref. 4). More recently, the roll-axis air combat limits 
were specifically investigated in a piloted simulation of pitch and roll requirements for air combat (Ref. 5). This simulation verified the $3.5 \mathrm{rad} / \mathrm{sec}$ Level 1 boundary but suggested the Level 2 boundary should be raised to 1 $\mathrm{rad} / \mathrm{sec}$. In all these aforementioned investigations the effect of time delay variation was not included. Hence the data from these studies is only pertinent in establishing where the portion of the boundaries intersect the abscissa. The shape of the boundaries above the vertical portion, i.e., the curved portion for phase delays above $0.15 \mathrm{sec}$, has been established from data applicable to the hover and low speed requirements. In fact, the shape of the roll-axis air combat boundaries are identical to the hover and low speed pitch and roll target acquisition and tracking boundaries. The supporting data for the curvature in these boundaries comes from two experiments: an in-flight pitch tracking study (Ref. 6); and a ground-based pitch tracking study (Ref. 7). Based on these two studies, supporting data for curving the boundaries over for high phase delays and bandwidths is somewhat questionable.

\section{All Other MTE's - VMC and Fully Attended Operations}

The forward flight All Other MTE bandwidth limits were established from two flight test experiments (Refs. 8,9). In these experiments the primary variable was roll damping. The effects of time delay were not included and hence the data from these studies is also only pertinent in establishing where the vertical portion of the boundaries intersect the abscissa. The curved portion of the boundaries for the forward flight All Other MTE's are identical to those in the hover and low speed requirements. The hover and low speed roll-axis bandwidth supporting data comes from an in-flight experiment (Ref. 10) using the Canadian Institute for Aerospace Research variablestability Bell 205 helicopter. This experiment included rate command and attitude command control response types. A variety of hover and low speed tasks were performed but the boundaries were drawn based on the handling qualities ratings from a sidestep task. The criteria boundaries are primarily based on data which does not cover the area of high bandwidth and high phase delay configurations. In addition, there may be some questions conceming the applicability of the evaluation task related to small amplitude precision tracking.

\section{Miscellaneous Hellcopter Data}

Singular data points achieved in previous tests by the U.S. Army (Ref. 11) and DLR (Ref. 12) are marked in
Figure 5. Recognizing the discrepancies between the pilot ratings for these data points and the criteria boundaries, a discussion was started about the need to extend the data base and to verify the Level boundaries. Additional tests were performed with a BO 105 fly-by-wire helicopter using an open loop technique to vary the bandwidth and phase delay. The achieved data points (Fig. 6) underline the request to extend the data base.

\section{Related Flxed Wing Requirements}

In the fixed-wing standard (Ref. 13), a bandwidth criterion is only defined for the pitch axis. Although the requirements for the pitch axis are not directly comparable with the roll-axis requirements, the fixed-wing criteria show a fundamental difference in the slopes of the boundaries. The requirements specify a limitation of the phase delay for high bandwith and an upper bandwidth limit whereas, the helicopter requirements allow a higher phase delay with higher bandwidth values without any upper limit for the bandwidth. An interesting aspect can be shown by superimposing the fixed wing requirements for equivalent roll-axis time delays to the phase delay and bandwidth parameters by using a first-order rate and a second-order attitude command system with pure time delay. The requirements for the equivalent time delays in this rough approximation correlate with a limitation on the phase delay (Fig. 7).

The above discussion highlights the need to verify and to extend the existing data and, if necessary, to refine the rotorcraft bandwidth boundaries.

\section{GROUND BASED AND AIRBORNE SIMULATOR}

This section will describe the ground-based and in-flight simulation facilities that were used for the pretests and the formal evaluations.

\section{Ground-Based Fllght SImulator}

The piloted ground-based simulation was conducted on the NASA Ames 6-degree-of-freedom Vertical Motion Simulator (VMS). Figure 8 illustrates the VMS and lists the operational limits of the motion system. The cockpit had a single pilot seat mounted in the center of the cab and four image presentation "windows" to provide outside imagery. The visual imagery was generated using a Singer Link DIG 1 Computer Image Generator (CIG). The CIG data base was carefully tailored to con- 
tain adequate macro-texture (i.e., large objects and lines on the ground) for the determination of the rotorcraft position and heading with a reasonable precision. A seat shaker provided vibration cueing to the pilot, with frequency and amplitude programmed as functions of airspeed, collective position, and lateral acceleration. Aural cueing was provided to the pilot by a WaveTech sound generator and cabmounted speakers. Airspeed and rotor thrust were used to model aural fluctuations. Standard helicopter instruments and controllers were installed in the cockpit.

Mathematical models of the following items were programmed in the simulation host computer: (1) filters for the cockpit controller commands, (2) trim capability, (3) stability command and augmentation system (SCAS), (4) dynamics of the helicopter, and (5) ground effects. The SCAS was a stability-derivative model with known dynamics and no coupling (Ref. 14), and the character of its response was easily manipulated by changing the stability derivatives. A buffer between the pilot's controls and the SCAS enabled setting the desired amounts of pure time delay. The baseline stick-to-visual delay was $70 \mathrm{msec}$.

\section{Airborne Flight SImulator ATTHeS}

The DLR Institute for Flight Mechanics has developed a helicopter in-flight simulator. The Advanced Technology Testing Helicopter System (ATTHeS) is based on a BO 105 helicopter (Fig. 9). The testbed is equipped with a full authority nonredundant fly-by-wire (FBW) control system for the main rotor and fly-by-light (FBL) system for the tail rotor. The testbed requires a two-person crew consisting of a simulation pilot and a safety pilot. The safety pilot is equipped with the standard mechanical link to the rotor controls whereas, the simulation pilot's controllers are linked electrically/optically to the rotor controls. The FBW/L actuator inputs, which are commanded by the simulation pilot and/or the control system, are mechanically fed back to the safety pilot's controllers. With this mechanization, the safety pilot is enabled to monitor the rotor control inputs. The testbed can be flown in three modes: (1) the FBW/L disengaged mode, where the safety pilot has the exclusive control, (2) the 1:1 mode, where the simulation pilot has the full authority to fly the baseline helicopter, and (3) the simulation mode, where the simulation pilot is flying a simulated helicopter command model with full authority. In the $1: 1$ and the simulation modes the flight envelope of the testbed is restricted to not lower than $50 \mathrm{ft}$ above the ground in hover and $100 \mathrm{ft}$ in forward flight.
For in-flight simulation purposes, the most promising method of a control system design is to force the host helicopter to respond on the pilot's inputs as an explicitly calculated command model. The ATTHeS explicit model following control system (MFCS) design provides the airborme simulator with the demanded level of simulation flexibility. A detailed description of the ATTHeS in-flight simulation system is given in References 15,16 . The capability of the ATTHeS simulator is described by a high quality of simulation fidelity up to a frequency of about $10 \mathrm{rad} / \mathrm{sec}$ in the roll axis. The level of decoupling which can be achieved with a decoupled command model is significantly lower than 10 percent of the on-axis response. For these tests, a control computer cycle time of $40 \mathrm{msec}$ was realized. A generated subcycle one-fifth of the frame time allowed refreshing of the FBW/L actuator inputs in a lower time frame than the main cycle which was $16 \mathrm{msec}$ for this bandwidth study. The equivalent time delay for the overall system due to high order rotor effects, actuators dynamics, computational time and pilot input shaping was 100 to $110 \mathrm{msec}$ in the roll axis and 150 to $160 \mathrm{msec}$ in the pitch axis related to first-order rate command responses.

\section{DEVELOPMENT OF SLALOM TRACKING TASK}

The objective of this study was to investigate the effects of time delay on the small amplitude $(<10 \mathrm{deg})$ roll attitude response to control inputs, i.e., the bandwidth criteria. This criteria is applicable to continuous precision tracking with aircraft attitude. A key to the success of this study was to develop an appropriate small amplitude precision tracking task that could be implemented both on the ground-based and on the in-flight simulator while considering the constraints of each. For the ground-based simulator, some of these constraints include a reduced field of view and visual resolution whereas, for the flight tests these include 100 feet minimum altitude. In adition, it was desired to keep the complexity of the task cueing to a reasonable level to minimize the building of exotic and expensive task cues. Based on previous slalom testing experience (Refs. 8,18), a modified slalom task with precise tracking phases through a set of gates was proposed (Fig. 10). This course layout included transition and precision tracking phases. The transition phases were intended to be a lower frequency disturbance with the main emphasis of the task being the higher frequency tracking 
phases just prior to and through the gates. The relative spacing between successive gates was established through the use of an inverse modelling technique (Ref. 19) that considered the aircraft response, speed, bank angle, and the time to travel between the gates. The width of a gate (desired performance) was three meters. In pre-tests on the VMS and with an operational BO 105 helicopter, the adequacy of the task was evaluated. It should be noted that due to the relative poor visual resolution in the VMS (approximately 0.35 cycles per milliradians (Ref. 20)), the task had to be flown at 50 feet instead of 100 feet.

Figure 11 shows a typical time history based upon flying through the VMS course. Also shown is a frequency domain plot of the lateral control input. From these one can see the lower frequency large amplitude inputs used in the transition between the gates and the higher frequency small amplitude control inputs that occur during the final acquisition and tracking through the gates. The flight test data show a very similar tendency with low frequency inputs between the gates and an additional peak in the power or amplitude spectrum, which is $1 \mathrm{~Hz}$ and higher, for the acquisition and tracking phases.

\section{CONDUCTION OF TESTS}

For the pilot evaluatios, a first-order rate command (RC) and a second-order attitude command (AC) response system was defined for both the roll and pitch axes. Table 1 shows the form of these command responses. A rate of climb response and a sideslip command were implemented for the vertical and the directional axes respectively. The response to the pilot's inputs were decoupled except for the terms formulating the turn coordination and the pseudo altitude hold. A feedforward to the collective was implemented as a function of the roll attitude. For the RC response, the primary experimental variables were the roll damping, $L_{p}$, and the time delay, $\tau$. For the $\mathrm{AC}$ response, the primary variables were the narural frequency, $\omega_{n}$, and the time delay, $\tau$. The relative damping was held constant at 0.7 . The pitch axis parameters were varied in harmony with the roll axis parameters. $A$ variation and selection of the optimal control sensitivity $\left(\mathrm{L}_{\delta}\right)$ values were defined in the VMS simulations.

This selection process covered a range of natural frequencies and dampings for the attitude and rate command response types. Initial in-flight evaluations confirmed these sensitivities.
To gain an initial impression of the task and the sensitivity to the experimental variables, piloted simulation tests were conducted on the VMS. The studied configurations together with pilot ratings are shown in Figure 12. The configurations are summarized in Table 2. The VMS results demonstrate the consistency between the RC and $A C$ ratings and support the premise that the bandwidth criteria is independent of the response type. These results also supported the selection of the flight test configuration matrices which are shown in Table 3.

The flight tests were conducted at the German Forces Flight Test Center (WTD 61) in Manching. Twenty-eight flight hours were performed within 10 days. Four test pilots, one each from DLR, U.S. Army, WTD 61, and DRA-Bedford were involved in the tests. All pilots were experienced test pilots. The U.S. Army pilot also performed the VMS evaluations.

The following signals were measured in the flight tests: (1) position of the helicopter in relation to the ground track course, (2) pilot control inputs, (3) angular attitudes and rates, (4) accelerations, (5) airspeed, and (6) MFCS internal signals like command to the actuators. Because of the limited space in the test helicopter, the tests had to be observed from the ground station. On two quicklook terminals selected onboard signals were displayed. Additionally, the helicopter position data was displayed online in relation to the tracking gates. The individually achieved task performance in the tests were computed using the helicopter track in relation to an idealized ground track. With this performance parameter, the effects of training and task performance could be checked. When the test pilot had obtained a nearly constant task performance in the training phase for a given test configuration, two evaluation runs were performed. This test technique was used to ensure the pilot ratings and comments were based on a pilot that was well trained for the task and the configuration. For each configuration, the pilot had to fill out a questionnaire and had to summarize his evaluation in a Cooper Harper handling qualities rating. The questions were related to task performance, pilot workload, and system response characteristics. At least two test pilots flew each configuration but when the difference in the two ratings was higher than one rating point an evaluation with a third pilot was conducted. This technique allowed the coverage of a high number of configurations.

In Figure 13, a comparison of measured ground tracks for a Level 1 and a Level 2 rated rate command system is shown. The track of the Level 2 configuration shows that problems occured in the acquisition and track- 
ing phases where the tracking performance was especially degraded through the second and the fourth gate. This change in the task performance correlates with the Cooper Harper rating scale and underlines the consistency of the ratings. In the Cooper Harper rating scale, a rating from 1 to 4 implies that a desired task performance can be achieved with increasing pilot compensation and ratings of 5 and 6 imply only adequate task performance can be achieved. A similar effect can also be seen in Figure 14 which shows time histories of selected attitute command system configurations to compare the rating consistency. In the measured pilot input and roll attitude signals of the Level 2 rated configuration, a slight tendency of pilot induced oscillation can be recognized. This Level 2 configuration had a natural frequency of $1.7 \mathrm{rad} / \mathrm{sec}$ and an additional time delay of $120 \mathrm{msec}$.

\section{DISCUSSION OF RESULTS}

To examine the bandwidth and phase delay values for the test configurations, a verification analysis was performed using the measured flight test data. Figure 15 demonstrates the high level of accuracy achieved in selected configurations with ATTHeS. For both rate command and attitude command responses the overall ATTHeS response tends to have an only slightly increased bandwidth value of about $0.1 \mathrm{rad} / \mathrm{sec}$ compared with the values calculated with the commanded models. The phase delays are approximated accurately within a spread of about $0.01 \mathrm{sec}$ which is within the accuracy of the phase delay assessment method. Summing up the verification results, it can be stated that ATTHeS met the commanded response configurations very well and that the flight test data are credible for an evaluation of the bandwidth requirements.

Figure 16 shows all the flight test Cooper-Harper handling qualities ratings for both response systems, rate and attitude command. A clear consistency of the required bandwidth and phase delay parameters for rate and attitude command systems is demonstrated. This consistency in the rate and attitude command ratings not only demonstrate the premise that the bandwidth criteria is independent of the response type but that the task was appropriate for investigating this criteria. Due to the technique to give the pilots sufficient flight time to familiarize themselves with the task and the configuration, the spread in the ratings for most configurations is not higher than one rating point which underlines the validity for the generated data.

In Figure 17 the averaged ratings of the flight tests and the VMS tests are presented together with recommended Level boundaries. There are several obvious observations. First and foremost, the shape of these recommended Level boundaries is dramatically different than those in the current ADS-33 requirements (see Fig. 3). In particular, these results suggest that there needs to be some upper limits on the phase delay parameter. These results also seem to agree, in concept, with the fixed-wing requirements. Specifically, considering only the flight test data for mid bandwidth configurations a limitation on the phase delay (lower than $0.1 \mathrm{sec}$ for Level 1 and about $0.17 \mathrm{sec}$ for Level 2) seems warranted. As the bandwidth increases, the flight data suggests even less amounts of phase delay are acceptable. Typical pilots' comments include: "I feel that time delay is more an effect" and "Low predictability due to time delay and rapid initial response." These comments are reflected in the degraded pilot ratings. The VMS data does not show this sensitivity in the phase delay as the bandwidth is increased and allows higher phase delays for the Level 2 mid bandwidth region. In the comparison of VMS and flight test data it should be taken into consideration that the VMS tests were performed with only a reduced number of configurations and one test pilot with the objective of evaluating the sensitivity of parameter variations for the definition of the flight test martrices.

Another observation from Figure 17 is that the vertical portions of the boundaries from the VMS and the flight data do not coincide which each other nor with those from the ADS-33C presented in Figure 3. For Level 1, the VMS data recommend at least a bandwidth value of about $3 \mathrm{rad} / \mathrm{sec}$ and the flight test data a value of 2.5 $\mathrm{rad} / \mathrm{sec}$. The ADS-33 Level 1 requirement is at least 3.5 $\mathrm{rad} / \mathrm{sec}$ for air combat and $2.0 \mathrm{rad} / \mathrm{sec}$ for All Other MTE's - VMC and fully attended operations. For Level 2, the VMS data recommend at least a bandwidth of $2 \mathrm{rad} / \mathrm{sec}$ and the flight test data a value of $1.5 \mathrm{rad} / \mathrm{sec}$. ADS-33 Level 2 requires at least $2.0 \mathrm{rad} / \mathrm{sec}$ for air combat and $0.5 \mathrm{rad} / \mathrm{sec}$ for All Other MTE's. It is speculated that the primary reason for these differences is related to the task bandwidth. It is very difficult to obtain a repeatable yet simple representative air target tracking task. This led to the development of the slalom ground tracking task used for this study. Based upon the pilots' comments, this task, in terms of task bandwidth, is probably somewhere between the air tracking and the All Other MTEs, as defined in the 
ADS-33. The aforementioned bandwidth differences between the flight data and the VMS data are also attributable to slight differences in the task bandwidth manifested through differences in cueing. The VMS task was performed from a height of 50 feet whereas, the flight task had to be performed at 100 feet. After the flight tests, the two attitude command configurations with a bandwidth of 2.48 and $3.08 \mathrm{rad} / \mathrm{sec}$ and no added time delay were reevaluated on the VMS at three different altitudes $(25,50$. $75 \mathrm{ft}$ ) to get more insight on the impact of altitude on task cueing using a computer generated visual system. The test data demonstrate that the altitude was an influencing factor. The pilot ratings were significantly degraded with increasing altitude and the best consistency in the ratings with the flight test ratings was achieved in the 25 foot cases. These data and the variation in the vertical portion of the bandwidth boundaries points out the sensitivity to task differences and the fact that further work is needed which should address a systematical evaluation of the dependency between task bandwidth and Level boundaries and a refinement of the task categorization.

An analysis of control activity was performed to gain additional insight into the effects of changes in the aircraft bandwidth on the pilot's control strategy relative to performing the slalom tracking task. If the aircraft bandwidth is sufficiently higher than the task demands, then the pilot can act as a pure gain (i.e., not apply lead compensation) to satisfactorily perform the task. As the aircraft bandwidth decreases, to maintain desired task performance the pilot must increase his compensation. This increased compensation, which equates to an increase in workload, can cause a degradation in handling qualities. If the aircraft bandwidth is further decreased, then even larger amounts of pilot comsenpation are not sufficient to achieve desired task performance standards. These relations are also considered in the Cooper Harper rating scale. For a rating up to 4 , the pilot can achieve desired task performance levels with increasing pilot compensation. Ratings of 5 and 6 mean that only adequate performance can be achieved. The pilot's lateral cyclic input power versus frequency (input auto-spectrum) was used to quantify the pilot's control activity and the effect of aircraft and task bandwidth.

The "pilot cut-off frequency," $\omega_{\text {co }}$, was defined as a measure of the pilot's control activity bandwidth. The approach to determining the pilot cut-off frequency was to generate a ratio of root mean square (RMS) values expressed as $\sigma_{\text {co }} / \sigma_{\text {total }}$, where $\sigma_{\text {co }}$ is the RMS value at the cut-off frequency. The value determined for this ratio was 0.707 .

$$
\left[\sigma_{\text {co }} / \sigma_{\text {total }}\right]^{2}=0.707^{2}=1 / \pi \int_{0}^{\omega_{c o}} G_{\delta \delta} d \omega
$$

where; $\quad \omega_{\text {co }}=$ pilot cut-off frequency

$\mathrm{G}_{\delta \delta}=$ auto spectrum of the lateral cyclic

control, $\delta_{\text {lat }}$

$\sigma_{\text {total }}=$ total RMS of $\delta_{\text {lat }}$

$\sigma_{\mathrm{co}}=(0.707) \sigma_{\text {total }}$

When the aircraft's bandwidth exceeds the task bandwidth, this pilot cut-off frequency, $\omega_{c o}$, approaches the pilot crossover frequency, $\omega_{c}$, and gives a good approximation of the task bandwidth. The pilot cut-off frequency is just the frequency at which $70.7 \%$ of the control input is accounted for, which is also the classic $-3 \mathrm{~dB}$ bandwidth for servomechanisms. An analysis program, CIFER (Ref. 21), developed at AFDD was used to analyze the VMS data. A similar analysis program, DIVA (Ref. 22), was used to analyze the flight data at DLR.

Figure 18 shows the cut-off frequency versus the aircraft control response bandwidth from the VMS simulation. For the high aircraft bandwidth cases, the pilot's cut-off frequency levels off to around $1.5 \mathrm{rad} / \mathrm{sec}$ which is representative of the task bandwidth. It's clear that for these high aircraft bandwidths the pilot is not using all of the aircraft capability. As the aircraft bandwidth drops below about $3.0 \mathrm{rad} / \mathrm{sec}$, the pilot's cut-off frequency starts to increase as the pilot trys to maintain task performance. Interestingly, the Level 1-2 boundary for the VMS task was about $3.0 \mathrm{rad} / \mathrm{sec}$. Finally, as the bandwidth drops below about $2.2 \mathrm{rad} / \mathrm{sec}$ the pilot can no longer or will not increase his cut-off frequencey to attain even adequate task performance (Level 3 ratings). In other words, there was insufficient margin between excess aircraft control bandwidth and the task demand. Reference 23 implies a positive margin must exist for desired or adequate task performance to be acheived.

Figure 19 shows the pilot cut-off frequency versus the aircraft control response bandwidth from the flight lest results for the same pilot who flew the VMS cases. Shown are the rate and attitude command cases with no additional time delay and with additional delays of 40,80 , $120,160 \mathrm{msec}$. In general, the flight test results show a trend similar to the VMS results, i.e., as the aircraft bandwidth decreases the pilot cut-off frequency increases. 
Based upon this data, the high aircraft bandwidth configurations indicate that the flight test task bandwidth may be around $2.1 \mathrm{rad} / \mathrm{sec}$. It should be pointed out the apparent scatter in the pilot's handling quality rating data on this plot has been manifested by the effects of large phase delay. In some Level 2 attitude command configurations, the pilot used relatively low cut-off frequencies to avoid the pilot induced oscillations (PIO's) that can occur with attitude command response types with time delay. The results of an analysis of the pilot control activity suggest that the slalom tracking task bandwidth was somewhere around two radians per second, maybe a little lower for the VMS and a little higher for the flight tests. Hence with the large excess aircraft bandwidth over the task bandwidth, as provided by the capability of ATTHeS, a very thorough and valid investigation could be conducted into the effects of bandwidth and time delay on helicopter rollaxis handling qualities.

\section{CONCLUSIONS}

A helicopter handling qualities study has been conducted to investigate the effect due to time delay. This roll-axis investigation was conducted as a collaborative effort between the U.S. Army's Aeroflightdynamics Directorate (ATCOM) and the German Institute for Flight Mechanics of DLR. A U.S. ground-based flight simulator was used to develop and refine a slalom ground tracking task and to perform preliminary handling quality evaluations. The German in-flight simulator, ATTHeS, a variable stability BO 105 helicopter was used to conduct the flight tests while covering a more complete set of configuration dynamics. In the flight tests rate and attitude command control response configurations were evaluated which included bandwidths between 1.5 and $4.5 \mathrm{rad} / \mathrm{sec}$ and additional time delays up to $160 \mathrm{msec}$. The results of this cooperative research indicate:

1) the individual benefits of both ground-based and in-flight simulation can be used in a complementary and time efficient manner,

2) the developed slalom ground tracking task provided a relatively high gain compensatory tracking task that was sensitive to changes in the bandwidth and phase delay parameters,

3) for the task evaluated, the consistency in the ratings between rate and attitude command response sys- tems verify the independence of the bandwidth parameters to control response type,

4) for the task evaluated, the shape of the Level boundaries for the bandwidth criteria in the U.S. Army's helicopter specification for handling qualities (ADS-33C) needs to be refined by placing upper limits on the phase delay parameter, $0.1 \mathrm{sec}$ for Level 1 and about $0.17 \mathrm{sec}$ for the Level 2 boundary, and

5) the variation in the vertical portion of the bandwidth Level boundaries between the ground-based simulation, the in-flight simulation, and the ADS-33 requirements points out the sensitivity to task bandwidth and the need for further research.

\section{REFERENCES}

1 "Handling Qualities Requirements for Military Rotorcraft," Aeronautical Design Standard - 33 (ADS33C), August 1989.

2 Cooper, G.E. and Harper, R.P., " The Use of Pilot Rating in the Evaluation of Aircraft Handling Qualities," NASA TN D-5153, April 1969.

3 McRuer, D.T. and Krendel, E.S., "Mathematical Models in Human Pilot Behavior," AGARD AG-188, January 1974.

${ }^{4}$ Decker, W.A., Morris, P.M., and Williams, J.N. " A Piloted Simulation Investigation of Yaw Dynamics Requirements for Turreted Gun Use in Low-Level Helicopter Air Combat," American Helicopter Society 44th Annual Fonum, Washington, DC, June 1988.

5 Whalley, M.S. and Carpenter, W.R., " A Piloted Simulation Investigation of Pitch and Roll Handling Qualities Requirements for Air-to-Air Combat," American Helicopter Society 48th Annual Forum, Washington, DC, June 1992.

${ }^{6}$ Houston, S.S. and Horton, R.I., " The Identification of Reduced Order Models of Helicopter Behaviour for Handling Qualities Studies," 13th European Rotorcraft Forum, Arles, France, September 1987. 
7 Aponso, B.L., Mitchell, D.G., and Hoh, R.H., "Simulation Investigation of the Effects of Helicopter Hovering Dynamics on Pilot Performance," Joumal of Guidance. Control, and Dynamics, Vol. 13, No. 1, Jan.Feb. 1990.

8 Corliss, L.D. and Carico, D.G., "A Flight Investigation of Roll Control Sensitivity, Damping, and Cross-Coupling in a Low-Altitude Lateral Maneuvering Task," NASA TM-84376, Dec. 1983.

9 Pausder, H.-J. and Gerdes, R.M., " The Effects of Pilot Stress Factors on Handling Qualities Assessments During U.S./German Helicopter Agility Flight Tests," 8th European Rotorcraft Forum, Aix-en-Provence, France, September 1982.

10 Mitchell, D.G., Hoh, R.H., and Morgan, J.M., "Flight Investigation of Helicopter Low-Speed Response Requirements," Lournal of Guidance. Control_and Dynamics, Vol. 12, No. 5, Sept.-Oct. 1989.

11 Tischler, M. et al., " Application of Flight Control System Methods to an Advanced Combat Rotorcraft," Royal Aeronautical Society International Conference on Helicopter Handling Qualities and Control, London, UK, November 1988.

12 Pausder, H.-J. and von Grünhagen, W., "Handling Qualities Evaluation for Highly Augmented Helicopters," AGARD-CP-508, Paper No. 26, 1990.

13 Hoh, R.H. et al., "Proposed MIL Standard and Handbook - Flying Qualities of Air Vehicles, Volume II: Proposed MIL Handbook," AFWAL-TR-82-3081, November 1982.

14 Lewis, M.S., Mansur, M.H., and Chen, R.T.N., "A Piloted Simulation of Helicopter Air Combat to Investigate Effects of Variations in Selected Performance and Control Response Characteristics," NASA TM89438, April 1987.

15 Pausder, H.-J., Bouwer, G., and von Grünhagen, W., "ATTHeS In-Flight Simulator for Flying Qualities
Research," DLR International Symposium on In-Flight Simulation for the 90's, Braunschweig, FRG, July 1991

16 Bouwer G., Pausder, H.-J., and von Grünhagen, W. "ATTHeS-A Helicopter In-Flight Simulator with High Bandwidth Capability," American Helicopter Society 48th Annual Forum, Washington, DC, June 1992.

17 Kaletka, J. and von Grünhagen, W., "Identification of Mathematical Derivative Models for the Design of a Model Following Control System," American Helicopter Society 45th Annual Forum, Boston, MA., June 1989.

18 Pausder, H.-J., "A Study of Roll Response Required in a low Altitude Slalom Task," 11 th European Rotorcraft Forum, London, UK, September 1985.

19 Whalley, M.S., "Development and Evaluation of an Inverse Solution Technique for Studying Helicopter Maneuverability and Agility," NASA TM-102889, USAAVSCOM TR 90-A-008, July 1991.

20 Blanken, C.L., Hart, D.C., and Hoh, R.H., " Helicopter Control Response Types for Hover and LowSpeed Near-Earth Tasks in Degraded Visual Conditions," American Helicopter Society 47th Annual Forum, Phoenix, AZ, May 1991.

21 Tischler, M.T. and Cauffman, M.G., "FrequencyResponse Method for Rotorcraft System Identification: Flight Application to BO 105 Coupled Rotor/Fuselage Dynamics," Loumal of the American Helicopter Society, Volume 37, Number 3, July 1992.

22 Wulff, G., "DIVA on VAX-Computers: Handbook Part 1 - Analysis of Time Dependent Data," DLR IB 11190/30, June 1990.

23 Heffley, R.K., Bourne, S.M., Curtiss , H.C., Jr., Hindson, W.S., and Hess, R.A., "Study of Helicopter Roll Control Effectiveness Criteria," NASA Contractor Report 177404, USAAVSCOM TR-85-A-5, April 1986. 
Table 1. Form of command responses

\begin{tabular}{|c||c|c|}
\hline Axis & Rate Command & Attitude Command \\
\hline \hline Pitch & $\frac{q}{\delta_{x}}=\frac{M_{\delta_{x}} e^{-\tau s}}{\left(s+M_{q}\right)}$ & $\frac{\theta}{\delta_{x}}=\frac{M_{\delta_{x}} e^{-\tau s}}{\left(s^{2}+2 \zeta \omega_{\theta} s+\omega_{\theta}^{2}\right)}$ \\
Roll & $\frac{p}{\delta_{y}}=\frac{L_{\delta y} e^{-\tau s}}{\left(s+L_{p}\right)}$ & $\frac{\phi}{\delta_{y}}=\frac{L_{\delta x} e^{-\tau s}}{\left(s^{2}+2 \zeta \omega_{\phi} s+\omega_{\phi}^{2}\right)}$ \\
\hline
\end{tabular}

Table 2. VMS commanded roll-axis configurations

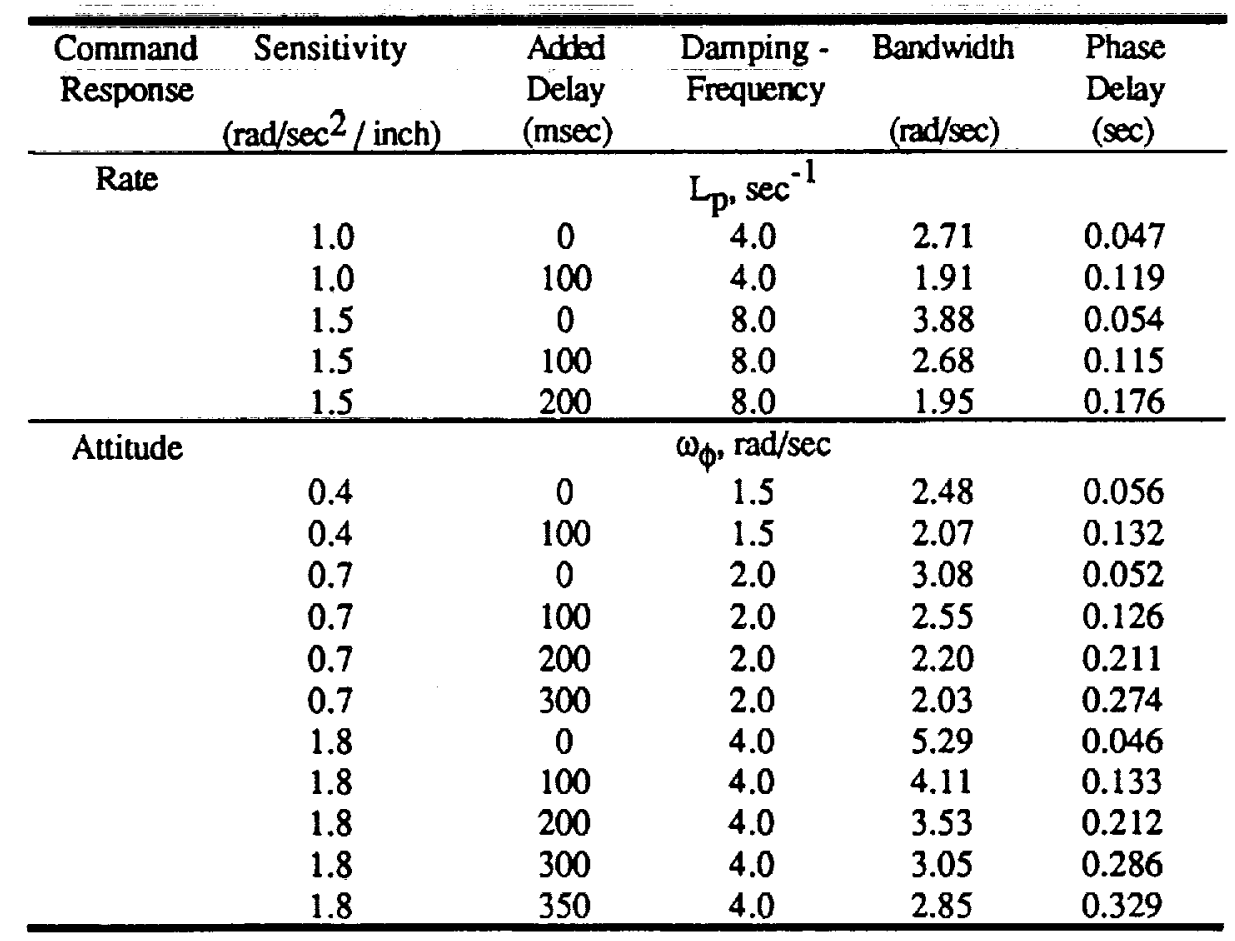


Table 3. ATTHeS commanded roll-axis configurations

\begin{tabular}{|c|c|c|c|c|c|}
\hline $\begin{array}{l}\text { Command } \\
\text { Response }\end{array}$ & $\begin{array}{c}\text { Sensitivity } \\
\left(\mathrm{rad} / \mathrm{sec}^{2} / \text { inch }\right)\end{array}$ & $\begin{array}{l}\text { Addod } \\
\text { Delay } \\
\text { (msec) } \\
\end{array}$ & $\begin{array}{l}\text { Damping - } \\
\text { Frequency }\end{array}$ & $\begin{array}{l}\text { Bandwidth } \\
(\mathrm{rad} / \mathrm{sec})\end{array}$ & $\begin{array}{l}\text { Phase } \\
\text { Delay } \\
(\mathrm{sec})\end{array}$ \\
\hline Rate & $\begin{array}{l}0.085 \\
0.093 \\
0.093 \\
0.100 \\
0.100 \\
0.100 \\
0.115 \\
0.115 \\
0.115 \\
0.130 \\
0.130 \\
0.130 \\
0.130 \\
0.145 \\
0.145 \\
0.145\end{array}$ & $\begin{array}{c}0 \\
0 \\
40 \\
0 \\
40 \\
80 \\
0 \\
40 \\
80 \\
0 \\
40 \\
80 \\
120 \\
0 \\
40 \\
80\end{array}$ & $\begin{array}{c}\mathrm{L}_{\mathrm{p}}, \sec ^{-1} \\
2.0 \\
3.0 \\
3.0 \\
4.0 \\
4.0 \\
4.0 \\
6.0 \\
6.0 \\
6.0 \\
8.0 \\
8.0 \\
8.0 \\
8.0 \\
10.0 \\
10.0 \\
10.0\end{array}$ & $\begin{array}{l}1.45 \\
1.93 \\
1.74 \\
2.34 \\
2.06 \\
1.85 \\
2.97 \\
2.55 \\
2.25 \\
3.44 \\
2.91 \\
2.52 \\
2.23 \\
3.82 \\
3.18 \\
2.73\end{array}$ & $\begin{array}{l}0.081 \\
0.081 \\
0.109 \\
0.080 \\
0.107 \\
0.134 \\
0.078 \\
0.105 \\
0.131 \\
0.077 \\
0.103 \\
0.127 \\
0.151 \\
0.076 \\
0.101 \\
0.125\end{array}$ \\
\hline Attitude & & & $\omega_{\phi}, \mathrm{rad} / \mathrm{sec}$ & & \\
\hline$(\zeta=0.7)$ & $\begin{array}{l}0.060 \\
0.060 \\
0.060 \\
0.060 \\
0.060 \\
0.100 \\
0.100 \\
0.100 \\
0.180 \\
0.180 \\
0.180 \\
0.180 \\
0.180 \\
0.300 \\
0.300\end{array}$ & $\begin{array}{c}0 \\
40 \\
80 \\
120 \\
160 \\
0 \\
40 \\
80 \\
0 \\
40 \\
80 \\
120 \\
160 \\
0 \\
40\end{array}$ & $\begin{array}{l}1.7 \\
1.7 \\
1.7 \\
1.7 \\
1.7 \\
2.3 \\
2.3 \\
2.3 \\
3.0 \\
3.0 \\
3.0 \\
3.0 \\
3.0 \\
4.0 \\
4.0\end{array}$ & $\begin{array}{l}2.49 \\
2.34 \\
2.20 \\
2.11 \\
2.02 \\
3.17 \\
2.95 \\
2.77 \\
3.89 \\
3.58 \\
3.34 \\
3.14 \\
2.97 \\
4.80 \\
4.38 \\
\end{array}$ & $\begin{array}{l}0.083 \\
0.114 \\
0.145 \\
0.175 \\
0.206 \\
0.084 \\
0.114 \\
0.145 \\
0.084 \\
0.115 \\
0.145 \\
0.176 \\
0.207 \\
0.084 \\
0.115 \\
\end{array}$ \\
\hline
\end{tabular}




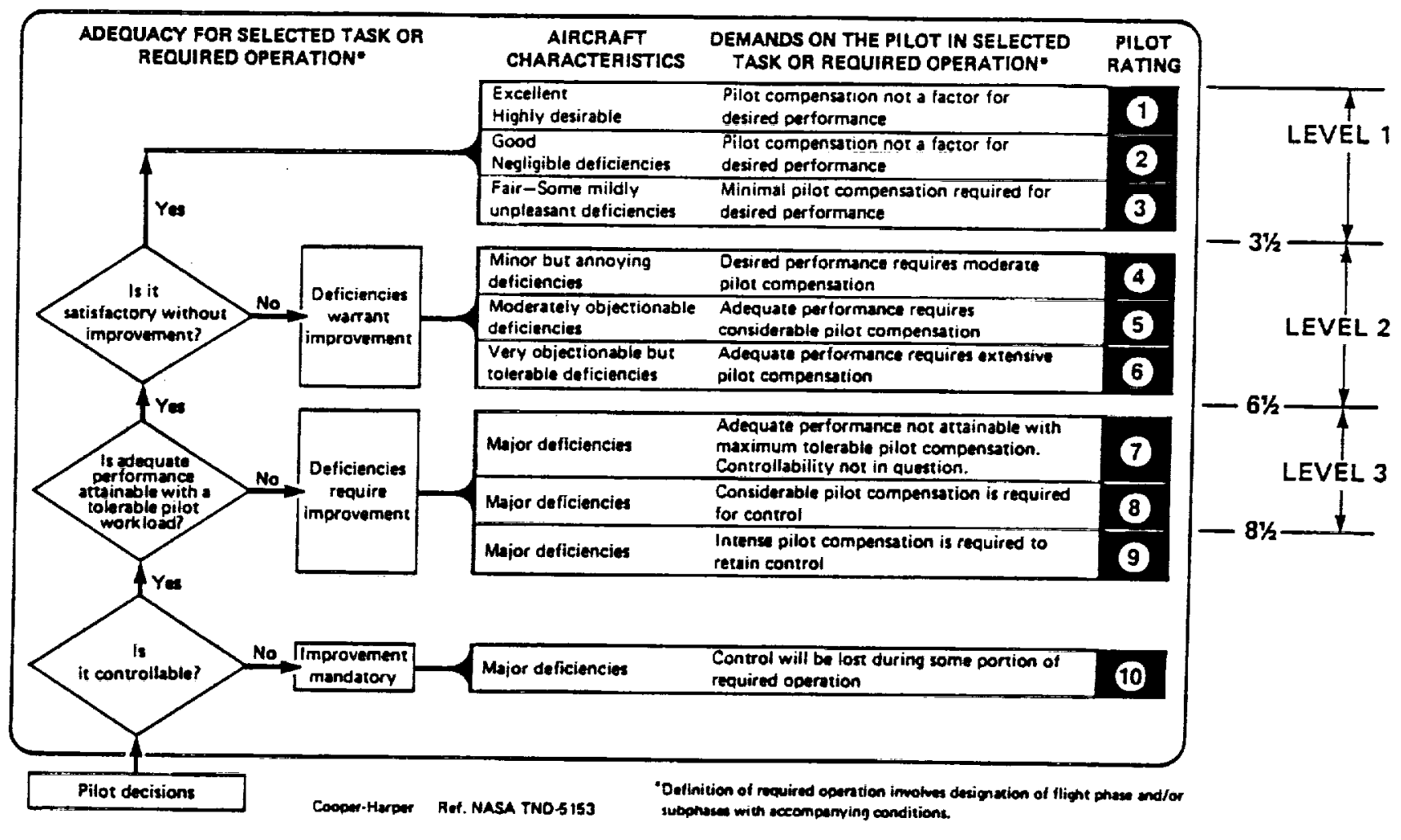

Figure 1. Definition of handling qualities Levels (from Ref. 1).

\section{BANDWIDTH}

- RATE

$\omega_{\mathrm{BW}}$ is lesser of $\omega_{\mathrm{BW}}$ aain and $\omega_{\text {BW }}$

- ATTITUDE COMMAND/ATTITUDE HOLD

$\omega_{\mathrm{BW}} \equiv \omega_{\mathrm{BW}}$ phase

\section{PHASE DELAY}

$\tau_{p}=\frac{\Delta \Phi 2 \omega_{180}}{57.3\left(2 \omega_{180}\right)}$

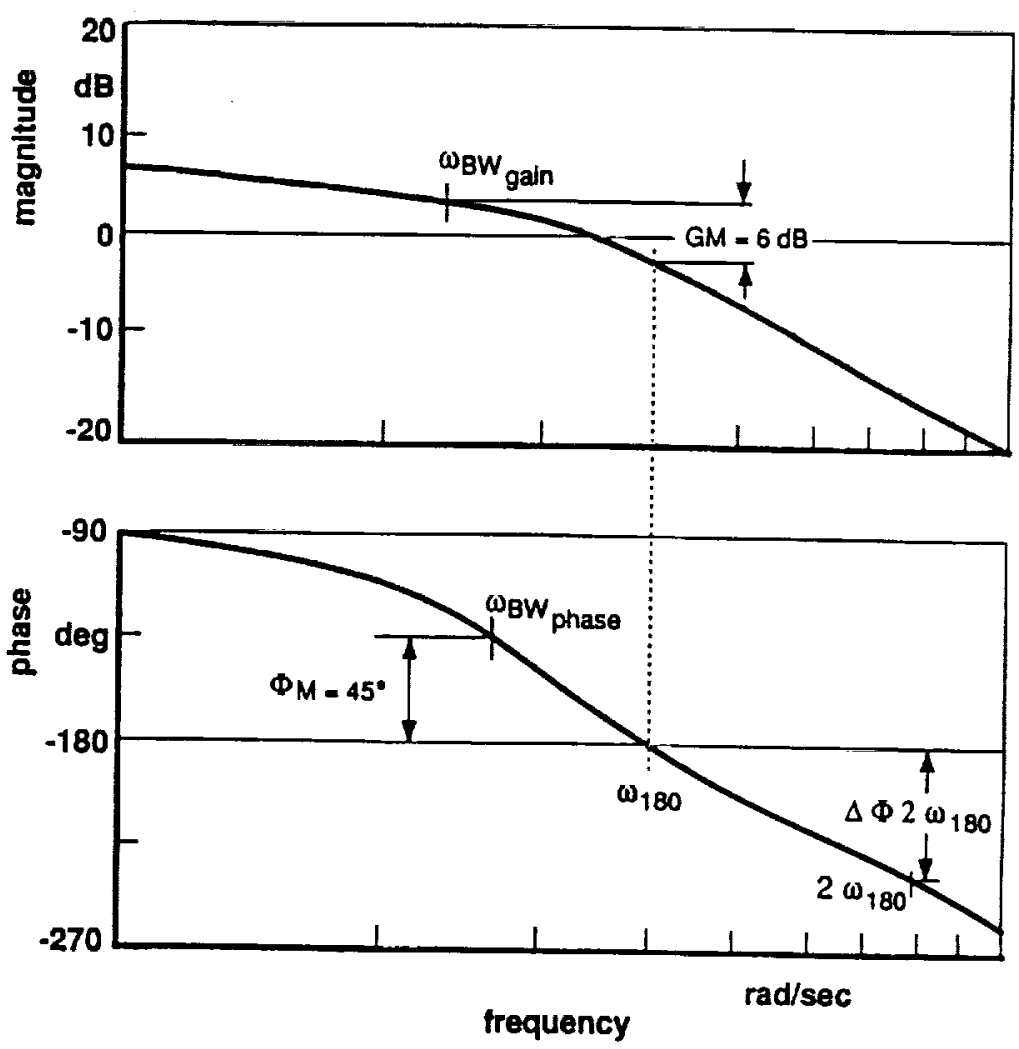

Figure 2. Definition of bandwidth and phase delay. 


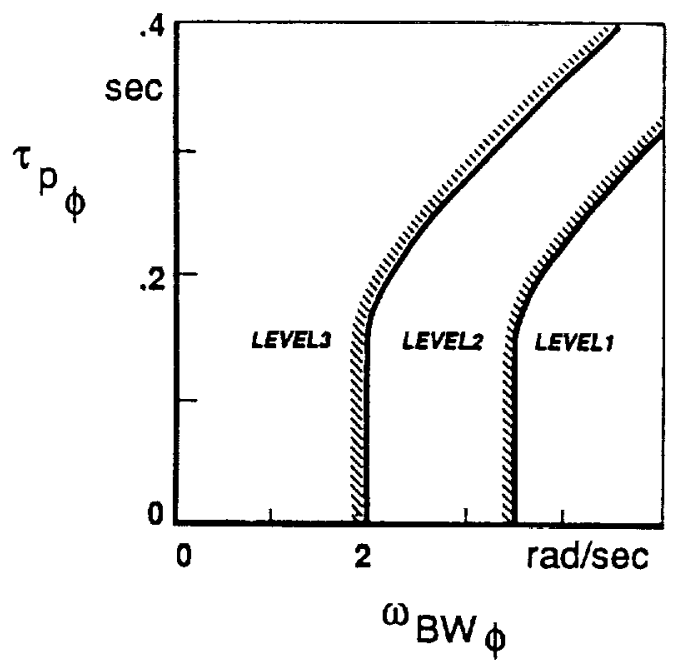

a) Air Combat

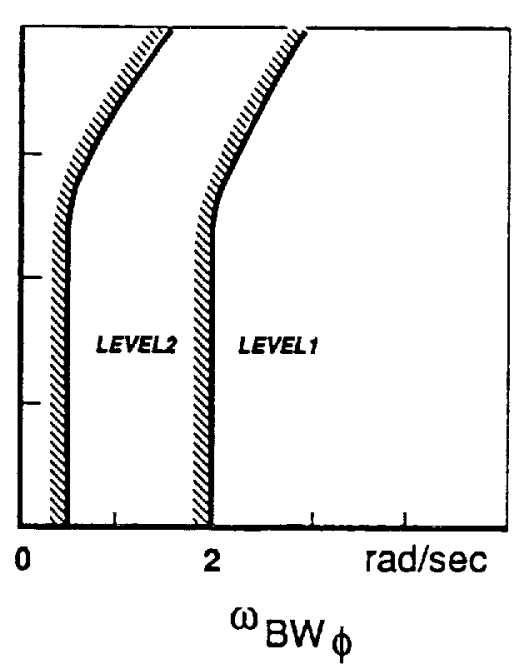

b) All Other MTE's - VMC and full attended operations

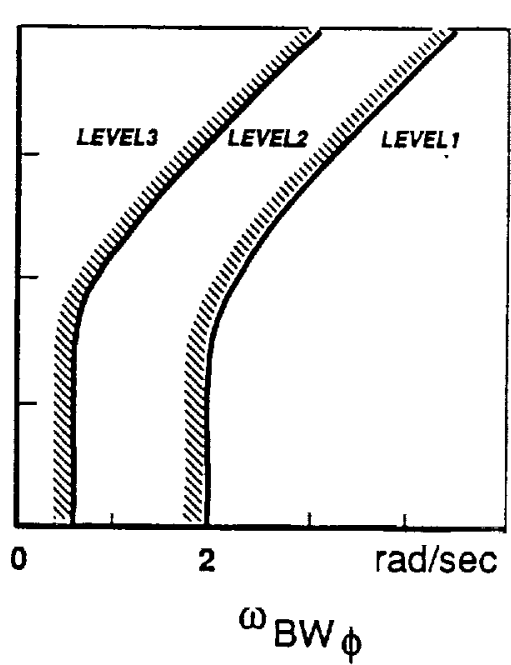

c) All Other MTE's - IMC and/or divided attention operations

Figure 3. ADS-33C requirements for small-amplitude attitude changes (roll-axis forward flight).

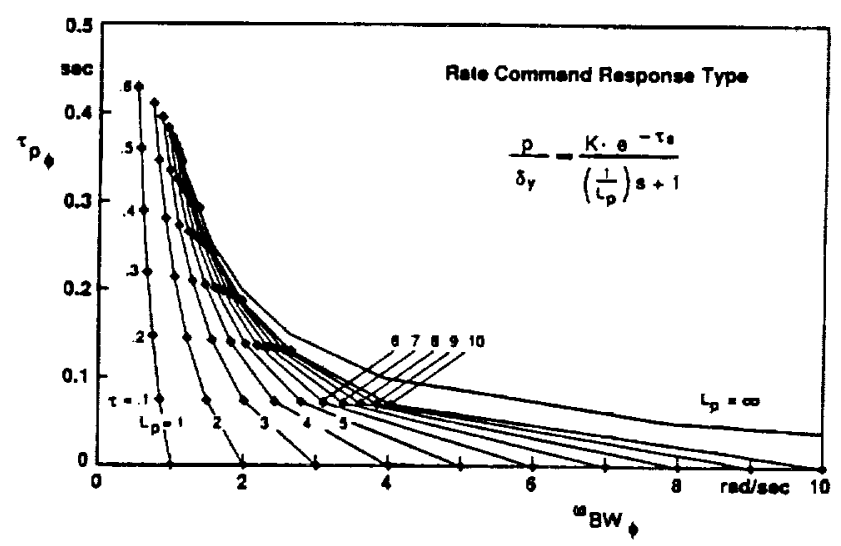

a) Rate command

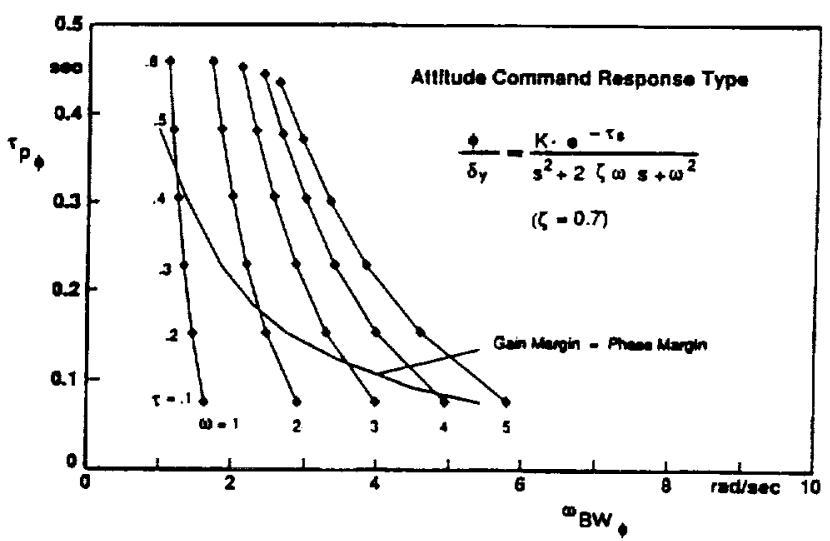

b) Attitude command

Figure 4. Effect of time delay on bandwidth and phase delay. 


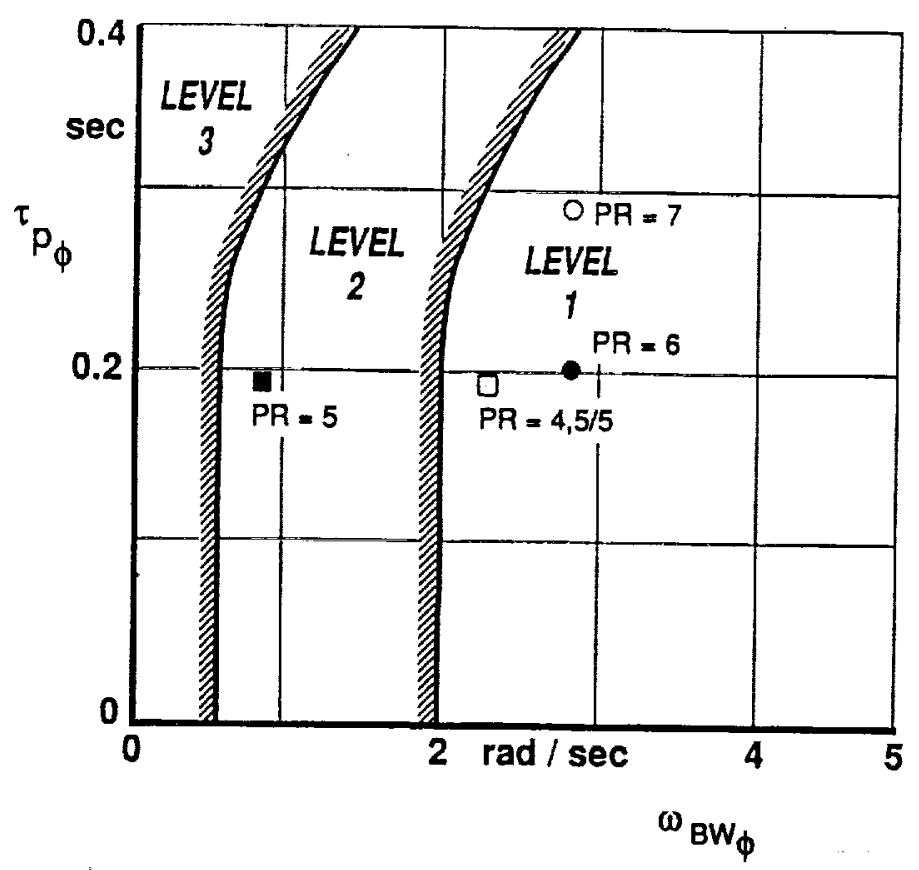

- ADOCS

Landing / Liftoff

$A D O C S$

60 knot Quickstop

- ATTHeS Previous Design

$\mathrm{RC}$

60 knot Slalom

- ATTHeS Previous Design

ACAH

60 knot Slalom

Figure 5. ADOCS (Ref. 11) and ATTHeS (Ref. 12) data points.

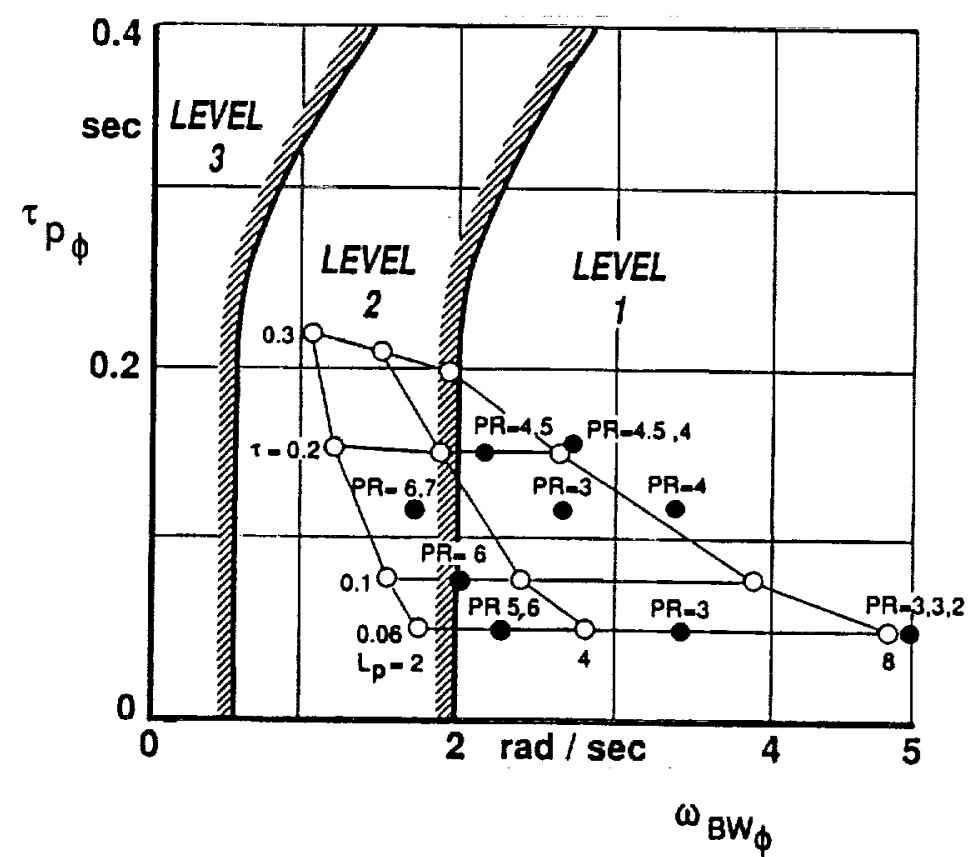

O Mapping for RC-Response $=\frac{K \cdot \theta-\tau s}{\frac{1}{L_{p}} \cdot s+1}$

- Realized RC-Response (open loop)

Figure 6. Slalom evaluation data (BO $105 \mathrm{FBW} / \mathrm{L}$ open-loop). 


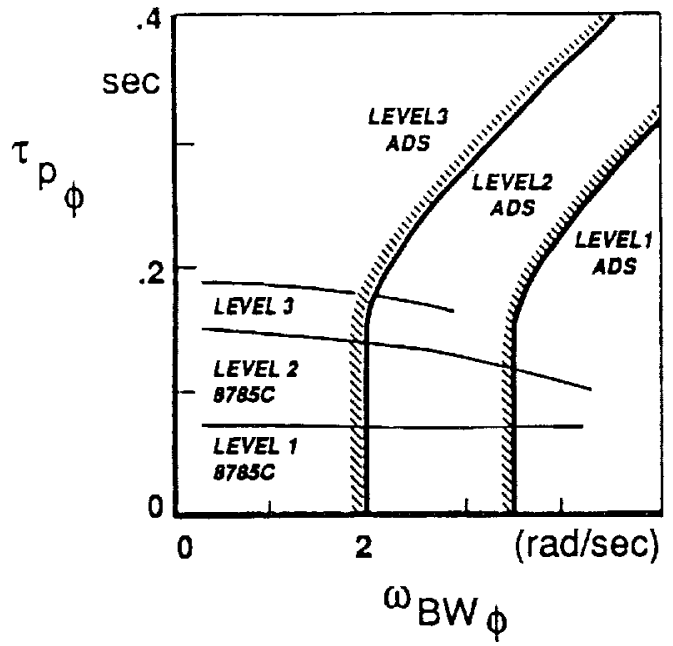

a) Air Combat

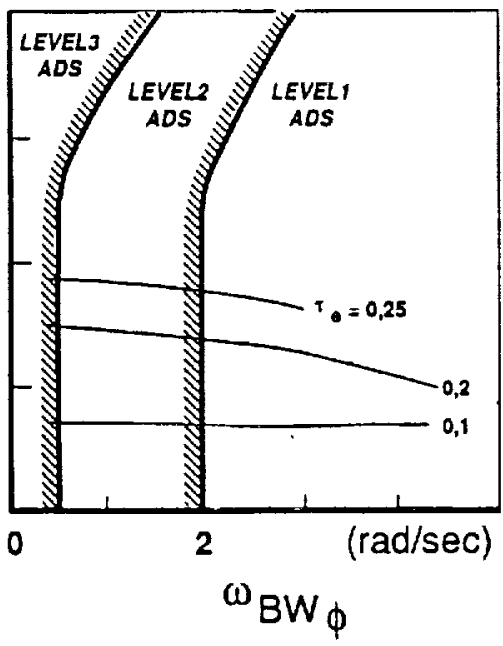

b) All Other MTE's - VMC and full attended operations

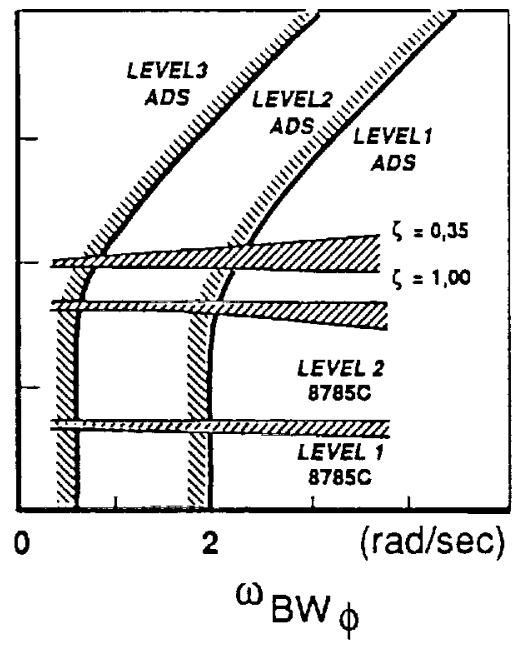

c) All Other MTE's - IMC and/or divided attention operations

Figure 7. Fixed-wing equivalent time delay requirements mapped onto the rotorcraft bandwidth requirements (assumes: first-order Rate command response and second-order Attitude command response).

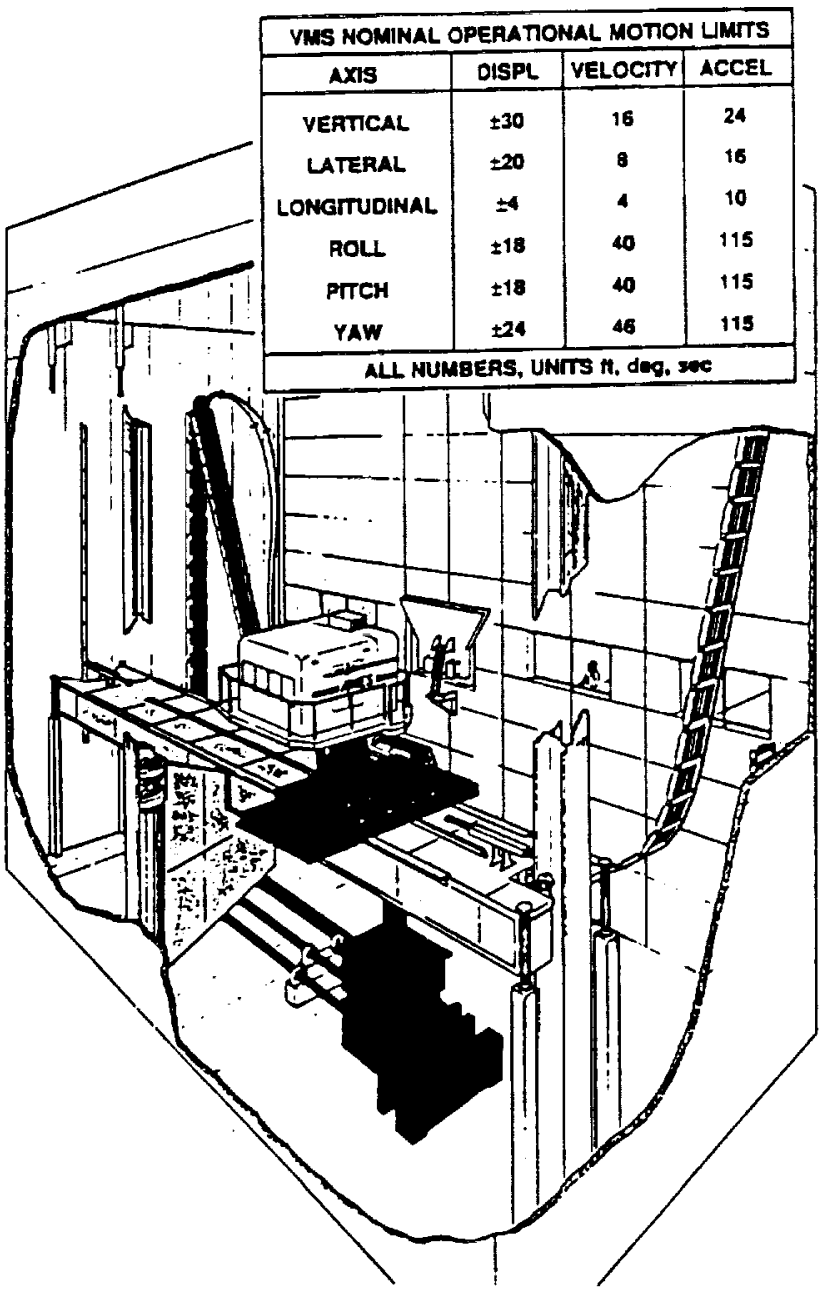

Figure 8. NASA Ames Research Center Vertical Motion Simulator (VMS).

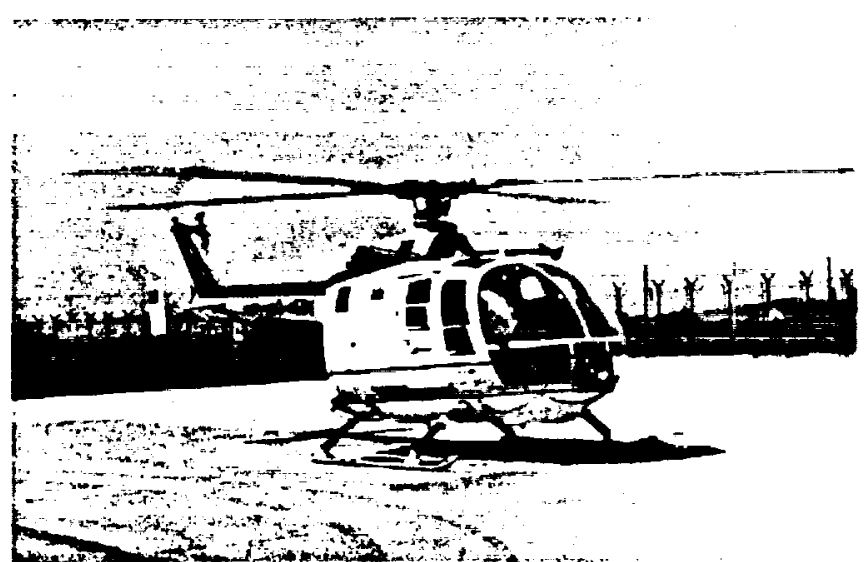

Figure 9. DLR in-flight simulator ATTHeS. 


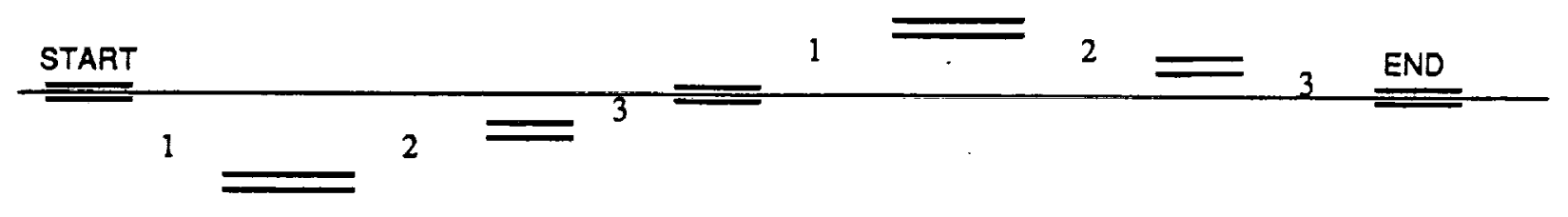

Gates:

3 seconds

$=$

$90 \mathrm{~m} / 295 \mathrm{ft}$

5 seconds

$150 \mathrm{~m} / 490 \mathrm{ft}$
Distances between Gates:

( $x, y$ measured from previous Gate)

$1(5 \mathrm{sec})$ x: $153 \mathrm{~m} / 500 \mathrm{ft}$ y: $10 \mathrm{~m} / 32 \mathrm{ft}$

$2(3 \mathrm{sec})$ x: $92 \mathrm{~m} / 300 \mathrm{ft} \quad$ y: $3.5 \mathrm{~m} / 12 \mathrm{ft}$

$3(5 \mathrm{sec})$ x: $153 \mathrm{~m} / 500 \mathrm{ft}$ y: $6.5 \mathrm{~m} / 20 \mathrm{ft}$

Figure 10. Slalom tracking course (times shown for 60 knots).
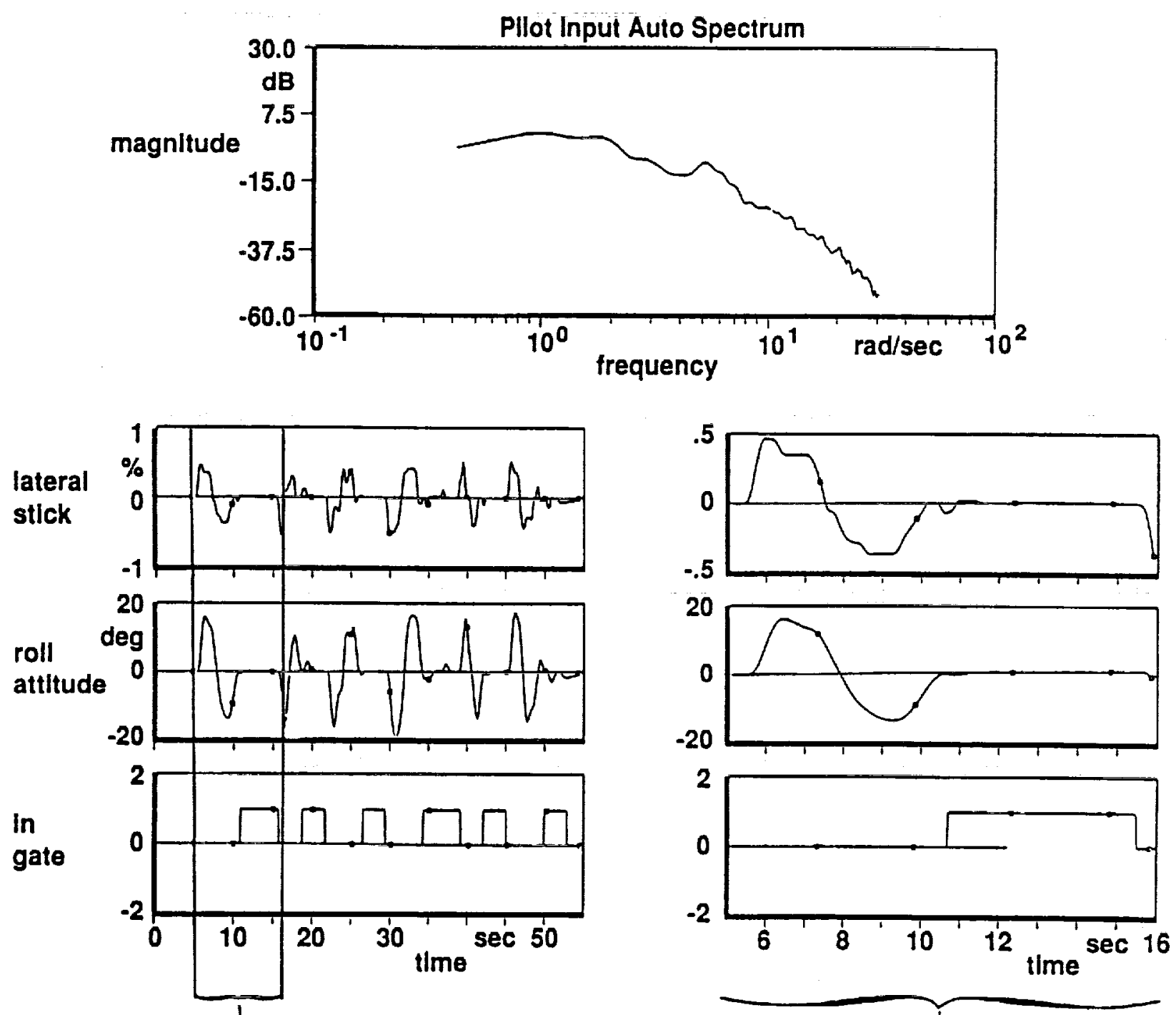

Figure 11. Time history and frequency plot from VMS test. 


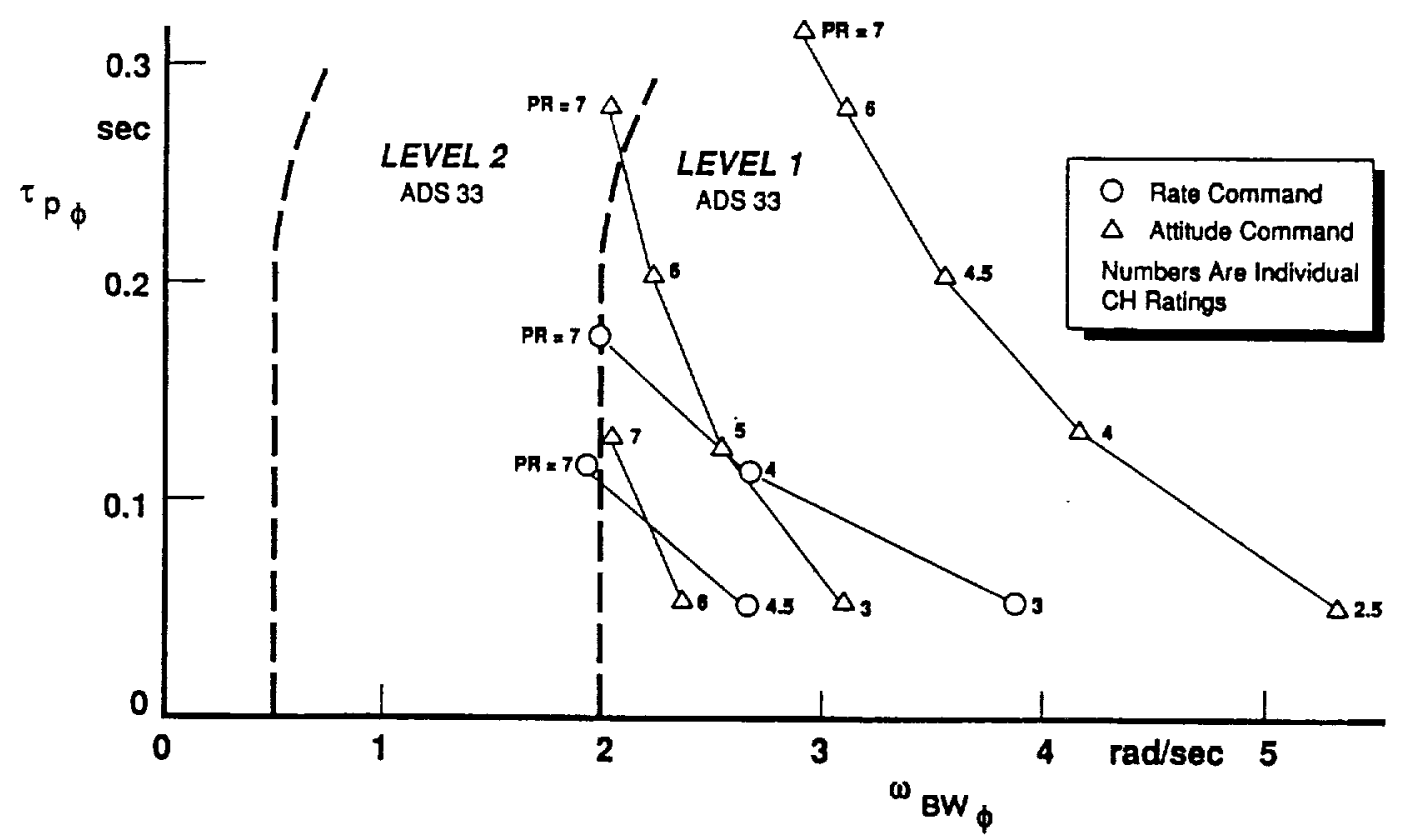

Figure 12. VMS data points.

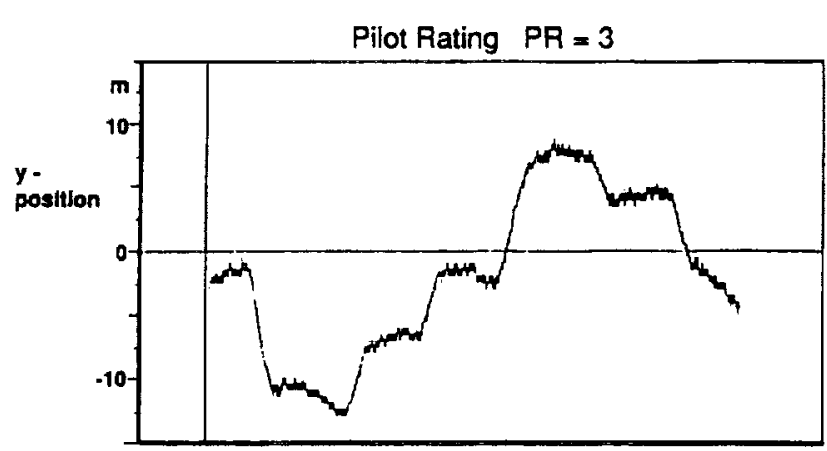

Pilot Rating PR $=5$
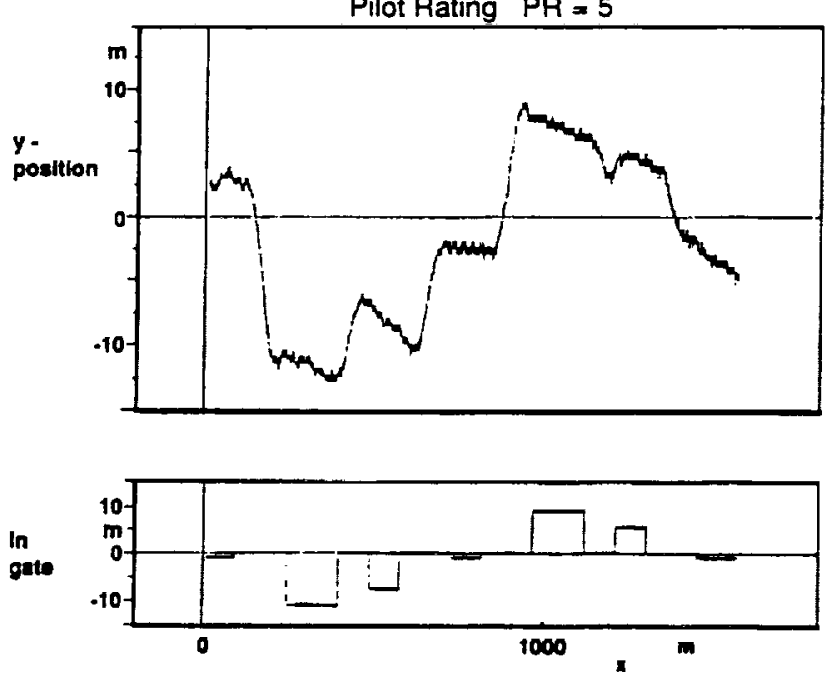

Figure 13. Comparison of ground tracks (RC in-flight).

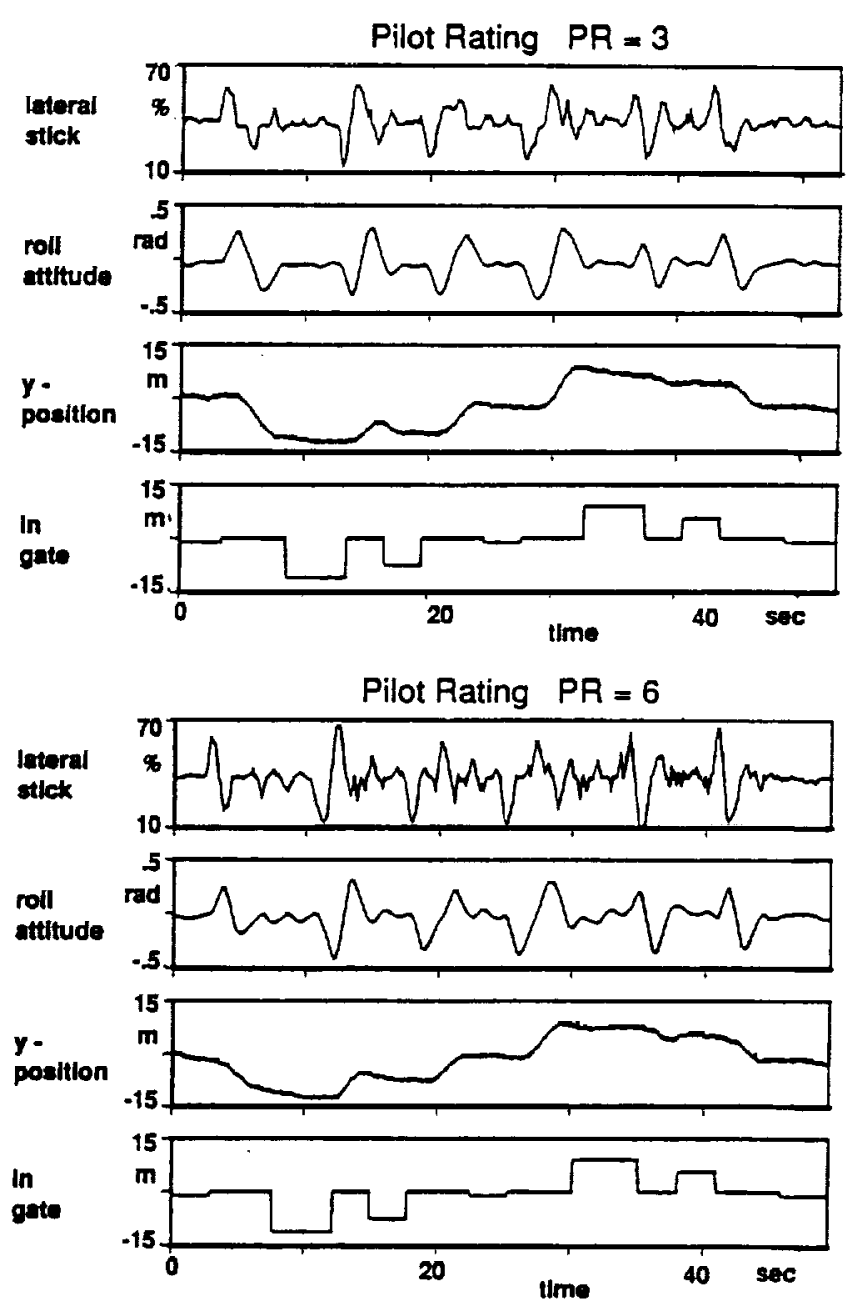

Figure 14. Comparison of time histories ( $A C$ in-flight). 

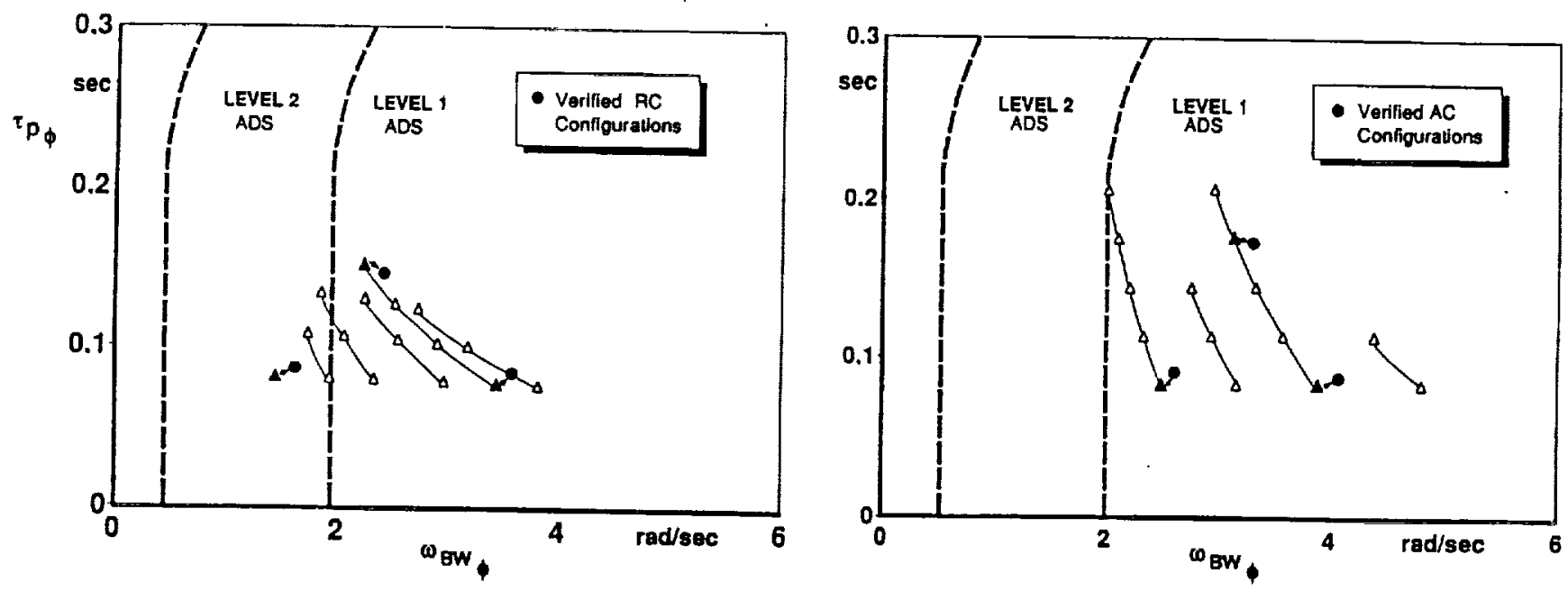

Figure 15. Verification of flight test configurations.

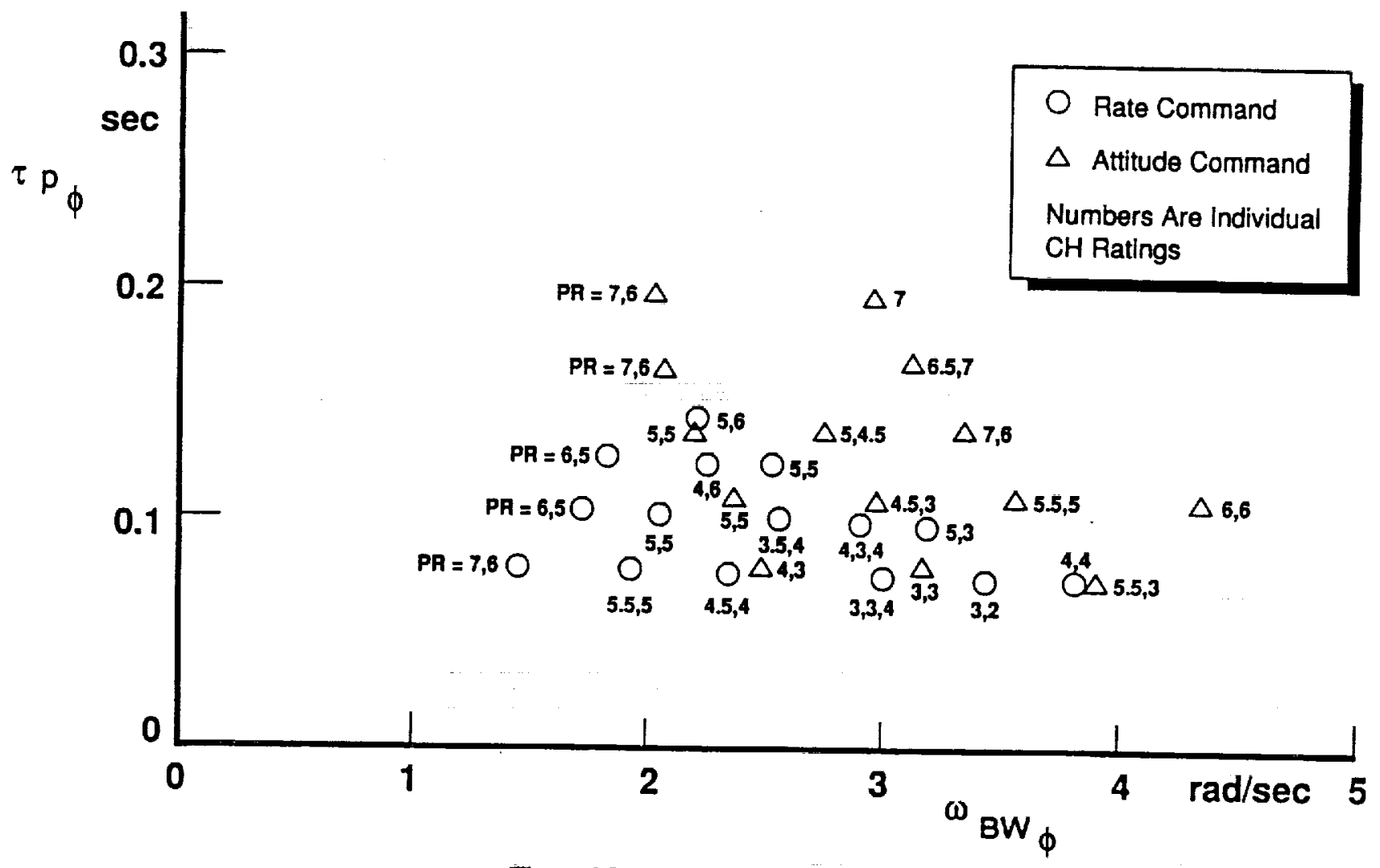

Figure 16. Flight test data points. 


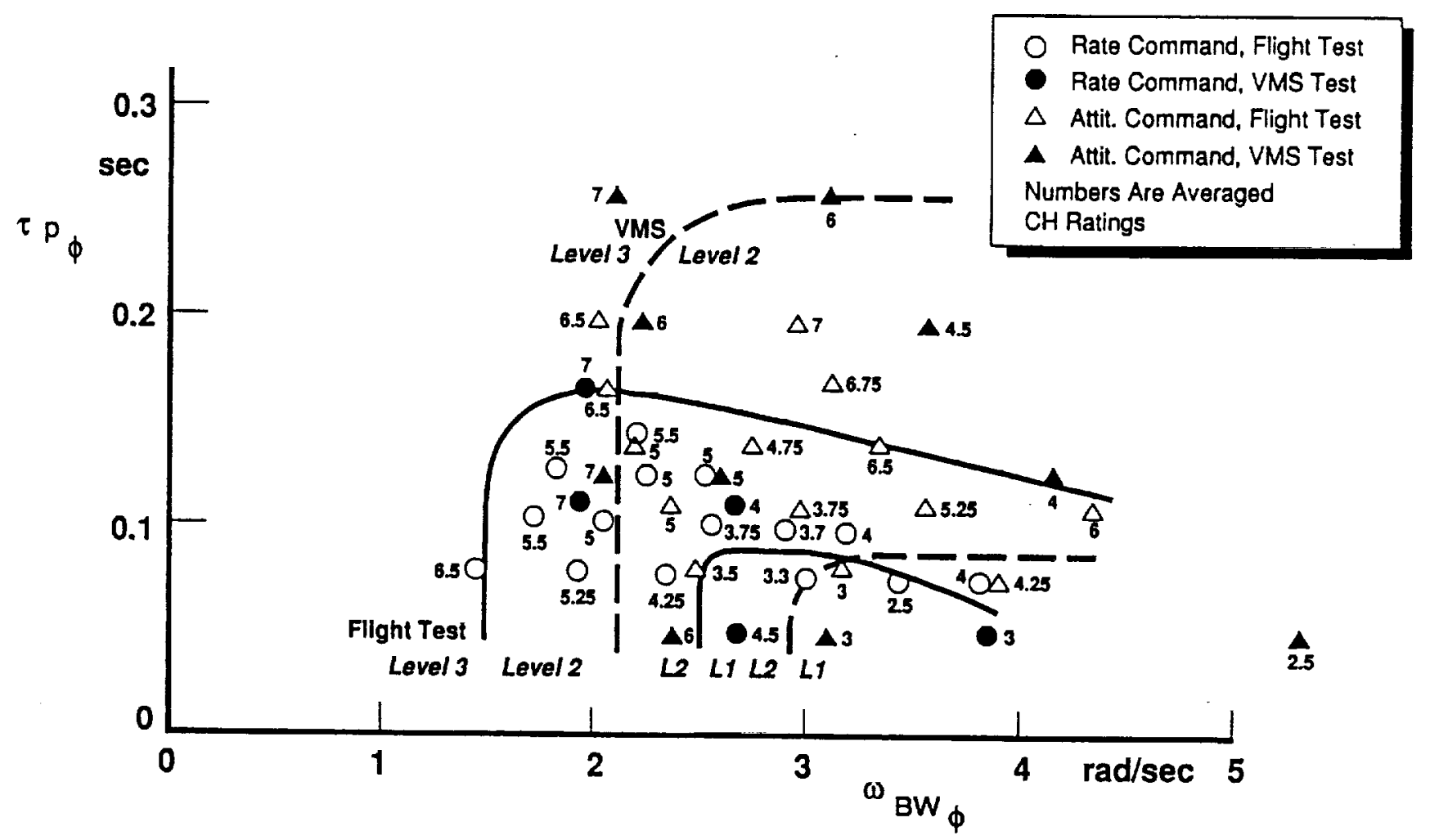

Figure 17. Summarized evaluations.

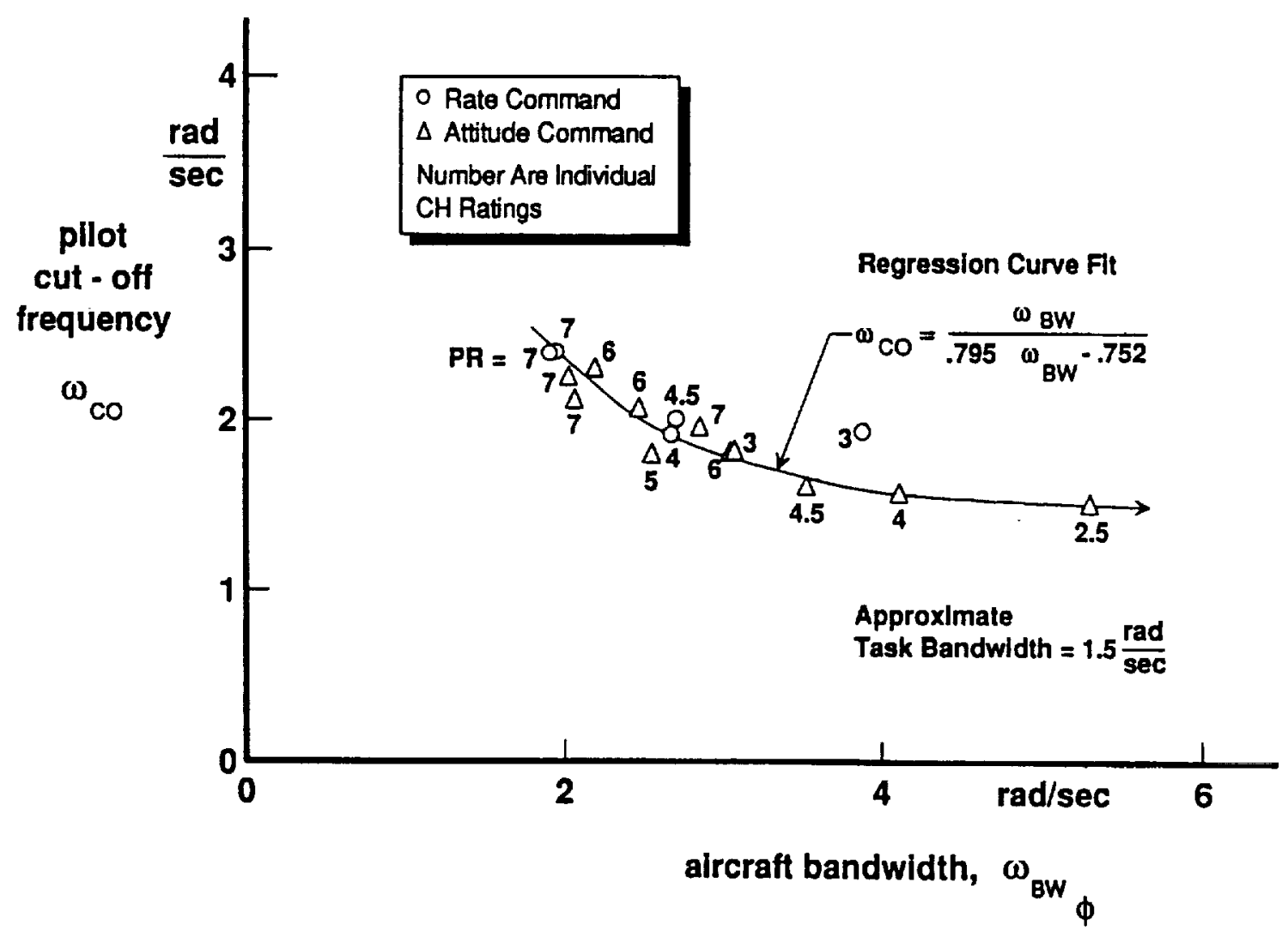

Figure 18. Pilot cut-off frequency data from VMS tests. 


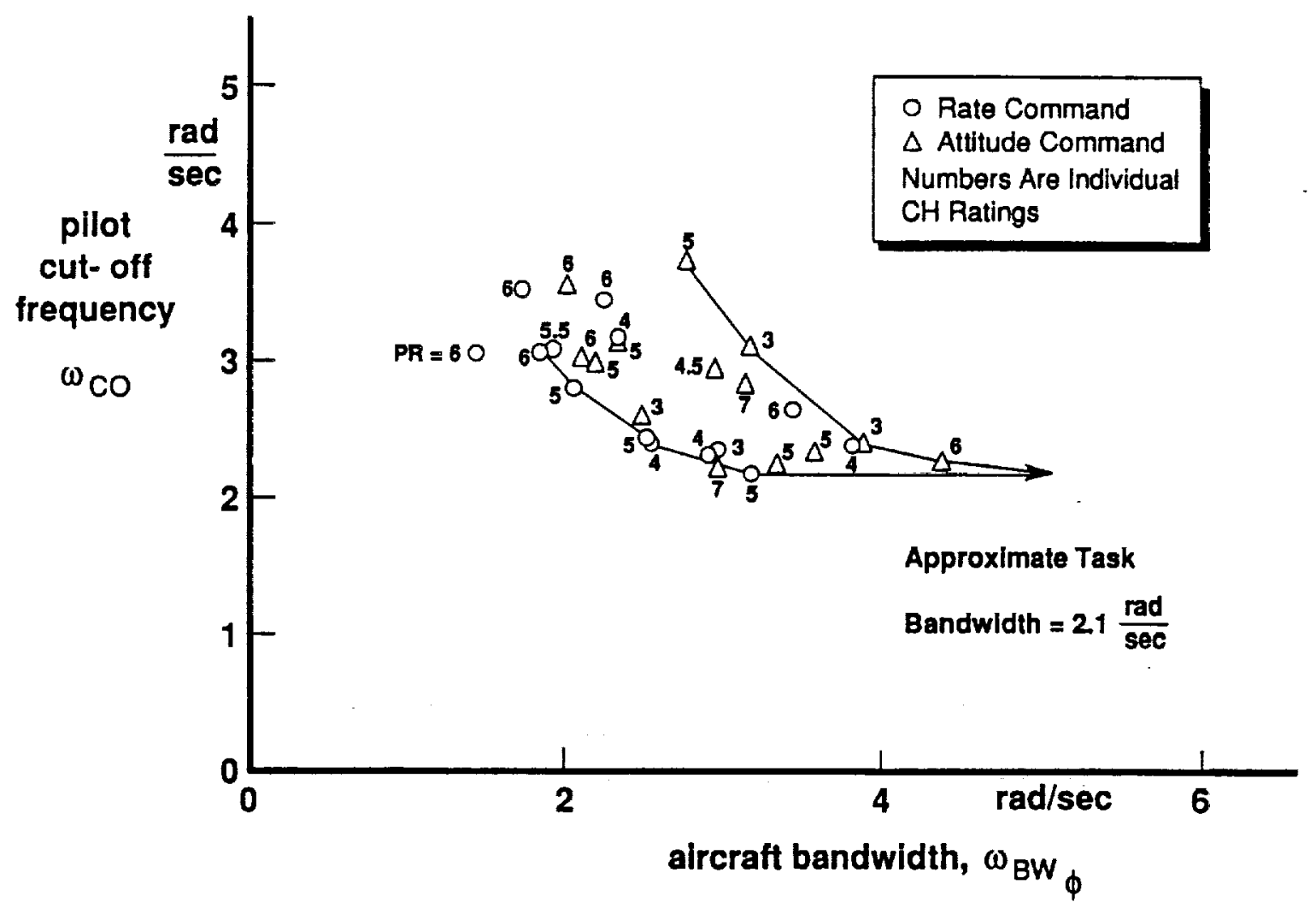

Figure 19. Pilot cut-off frequency data from flight tests (one pilot). 


\section{Session 2}

\section{Assessing New Technologies}




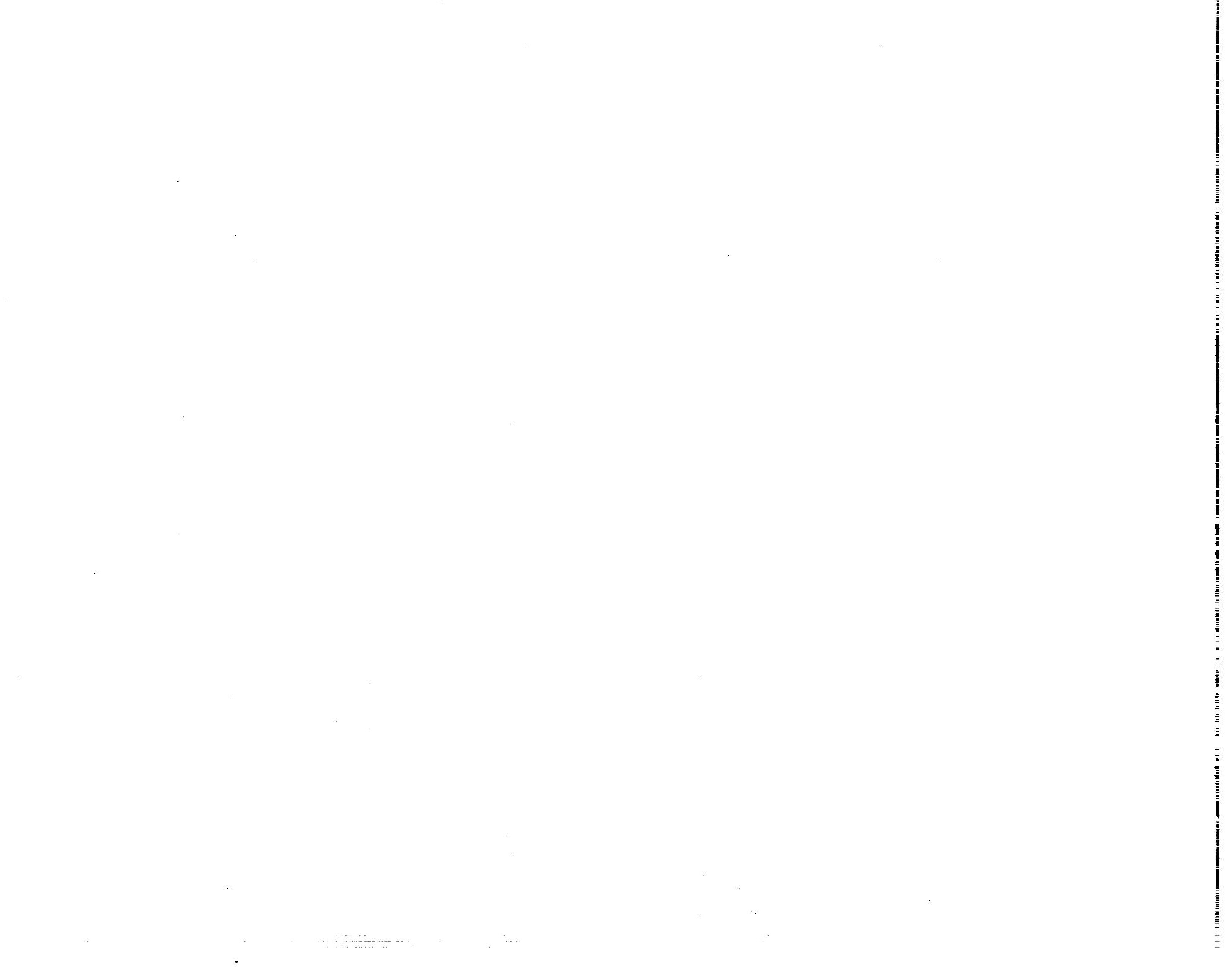

